\title{
$\mathrm{J}$

\section{Homogenous Pd-Catalyzed Asymmetric Hydrogenation of Unprotected Indoles: Scope and Mechanistic Studies}

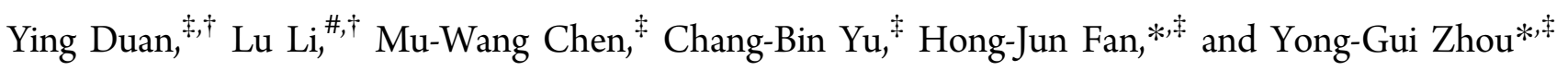 \\ ${ }^{\ddagger}$ State Key Laboratory of Molecular Reaction Dynamics, Dalian Institute of Chemical Physics, Chinese Academy of Sciences, Dalian \\ 116023, China \\ ${ }^{\#}$ State Key Laboratory of Fine Chemicals, Institute of Coal Chemical Engineering, School of Chemical Engineering, Dalian University \\ of Technology, Dalian 116024, China
}

\section{Supporting Information}

ABSTRACT: An efficient palladium-catalyzed asymmetric hydrogenation of a variety of unprotected indoles has been developed that gives up to $98 \%$ ee using a strong Brønsted acid as the activator. This methodology was applied in the facile synthesis of biologically active products containing a chiral indoline skeleton. The mechanism of Pd-catalyzed asymmetric hydrogenation was investigated as well. Isotope-labeling reactions and ESI-HRMS proved that an iminium salt formed by protonation of the $\mathrm{C}=\mathrm{C}$ bond of indoles was the significant intermediate in this reaction. The important proposed active catalytic $\mathrm{Pd}-\mathrm{H}$ species was observed with ${ }^{1} \mathrm{H}$ NMR spectroscopy. It was found that proton exchange between the $\mathrm{Pd}-\mathrm{H}$ active species and solvent trifluoroethanol (TFE) did not occur, although this proton exchange had been previously observed between metal hydrides and alcoholic solvents. Density functional theory calculations were also carried out to give further insight into the mechanism of Pd-catalyzed asymmetric hydrogenation of indoles. This combination of experimental and theoretical studies suggests that Pd-catalyzed hydrogenation goes through a stepwise outersphere and ionic hydrogenation mechanism. The activation of hydrogen gas is a heterolytic process assisted by trifluoroacetate of Pd complex via a six-membered-ring transition state. The reaction proceeds well in polar solvent TFE owing to its ability to stabilize the ionic intermediates in the $\mathrm{Pd}-\mathrm{H}$ generation step. The strong Brønsted acid activator can remarkably decrease the energy barrier for both $\mathrm{Pd}-\mathrm{H}$ generation and hydrogenation. The high enantioselectivity arises from a hydrogen-bonding interaction between $\mathrm{N}-\mathrm{H}$ of the iminium salt and oxygen of the coordinated trifluoroacetate in the eight-membered-ring transition state for hydride transfer, while the active chiral Pd complex is a typical bifunctional catalyst, effecting both the hydrogenation and hydrogen-bonding interaction between the iminium salt and the coordinated trifluoroacetate of Pd complex. Notably, the Pd-catalyzed asymmetric hydrogenation is relatively tolerant to oxygen, acid, and water.

\section{INTRODUCTION}

Chiral indolines are a significant class of alkaloids found in numerous bioactive compounds, such as pharmaceuticals, herbicides, and insecticides. ${ }^{1}$ These privileged motifs are key building blocks in the discovery of drugs. Although the demand for enantiomerically pure indolines is growing as time goes on, the methods to reach them are still limited. Because indoles have inherent stability and it is difficult to modify their aromatic properties, the journey from indoles to indolines has a long way to go. From the perspective of atom economy, asymmetric hydrogenation is the most direct and important way to achieve this process. ${ }^{2}$ As a huge family of heteroaromatic compounds, indoles have been shown to have important applications in organic synthesis, but they exhibited inertness in asymmetric hydrogenation until 2000.

In 2000, Ito, Kuwano, and co-workers ${ }^{3}$ reported the first example of asymmetric hydrogenation of $\mathrm{N}$-protected indoles using a $\mathrm{Rh} / \mathrm{Ph}$-TRAP complex as catalyst. Thereafter, $\mathrm{Rh} / \mathrm{Ph}$ TRAP $^{4}$ and $\mathrm{Ru} / \mathrm{Ph} \mathrm{TRAP}^{5}$ were found to be useful in asymmetric hydrogenation of indoles with an electron-withdrawing group on the nitrogen atom. The groups of Minnaard ${ }^{6}$ and Agbossou-Niedercorn ${ }^{7}$ then found that a complex of $\mathrm{Rh}$ and PinPhos or WalPhos as catalyst could also promote asymmetric hydrogenation of $\mathrm{N}$-protected indoles. The Ir/N,Pligand system was a desirable candidate as well, yet it gave barely satisfactory yields. ${ }^{8}$ There was virtually no development in the hydrogenation of simple indoles until our group introduced the strategy of Brønsted acid activation (Scheme 1). ${ }^{9}$ In that work, a powerful Pd catalyst system was selected due to its inertness to strong Brønsted acids. Subsequently, dehydration-triggered asymmetric hydrogenation ${ }^{10}$ and consecutive Brønsted acid/Pd-complex-promoted tandem reactions ${ }^{11}$ were also reported. Moreover, 3-(toluenesulfonamidoalkyl)indoles were synthesized and hydrogenated to form chiral indolines. ${ }^{12,13}$

Chiral Pd-based catalysts have achieved great successes in asymmetric hydrogenation of a large range of substrates, ${ }^{14}$ such as activated imines, ${ }^{15}$ enamines, ${ }^{16}$ functional ketones, ${ }^{17}$ olefins, ${ }^{18}$ and also heteroaromatic compounds. ${ }^{9-12,19}$ However,

Received: February 26, 2014

Published: April 30, 2014 
Scheme 1. Strong Brønsted Acid Activation Strategy for Asymmetric Hydrogenation of Unprotected Indoles

Previous Work: Asymmetric Hydrogenation of $\mathrm{N}$-Protected Indoles<smiles>[R]c1cc2ccccc2n1[Pb]</smiles>

$P G=T s, A c, B o c$

This Work: Asymmetric Hydrogenation of $\mathrm{N}$-Unprotected Indoles<smiles>[R]C1Cc2ccc(CC)cc2N1</smiles>

there are also some issues to be noted in these reactions. First, trifluoroethanol (TFE) has always been the best solvent, but that was challenged in the hydrogenation of simple indoles and pyrroles. Second, the detailed mechanism of Pd-catalyzed asymmetric hydrogenation remains to be elucidated, in terms of the fashion of hydrogen gas activation or the dissociation of $\mathrm{Pd}$ catalyst from the product. This question is relatively unexplored, in contrast to $\mathrm{Ir}_{-},{ }^{20} \mathrm{Ru}-,{ }^{21}$ or $\mathrm{Rh}^{22}$-catalyzed asymmetric hydrogenations. In this article, we extend the scope of Pdcatalyzed asymmetric hydrogenation of unprotected indoles and gain insight into the mechanism of Pd-catalyzed asymmetric hydrogenation by a combination of experimental and theoretical studies.

\section{RESULTS AND DISCUSSION}

Asymmetric Hydrogenation of Simple 2-Substituted Indoles. 2-Methylindole was chosen as the model substrate to assay the best reaction conditions for asymmetric hydrogenation, and $\mathrm{Pd}\left(\mathrm{OCOCF}_{3}\right)_{2} /(R)$-SegPhos complex was applied to begin the investigation. As shown in Table 1, hydrogenation does not occur in the absence of Brønsted acid (entry 1). To achieve full conversion and high enantioselectivity requires a stoichiometric amount of Brønsted acid to activate 2-methylindole. First, the effects of Brønsted acids on the reactivity and enantioselectivity were examined. Among the strong Brønsted acids, $\mathrm{PhSO}_{3} \mathrm{H}$, TsOH$\cdot \mathrm{H}_{2} \mathrm{O}$, and L-camphorsulfonic acid ( $\mathrm{L}-\mathrm{CSA}$ ) gave full conversions and moderate enantiomeric excess (ee) values (Table 1, entries 3, 4, and 6); LCSA gave full conversion and the highest enantioselectivity (entry $6,71 \%$ ee). In contrast, D-CSA with the opposite configuration gave product with $44 \%$ conversion and somewhat lower ee (entry $7,66 \%$ ee). These varied activities and ee values may ascribed to the different matching ability of the chiral ligand and the two CSAs. However, with weak Brønsted acids, such as benzoic acid and salicylic acid, either low turnover or low enantioselectivity was observed. Therefore, it was concluded that L-CSA was the best activator to promote this asymmetric hydrogenation, on the basis of the data in Table 1 . Second, the effect of solvent was evaluated, and it was found that solvent influenced both conversions and ee values dramatically (Table 1 , entries 6, 10-13). Fortunately, the combination of equal volumes of DCM and TFE resulted in full conversion and higher ee (Table 1 , entries 15 vs 14 and 16). Finally, examination of various bisphosphine ligands showed that $(R)$-H8-BINAP promoted the ee value to $91 \%$ (Table 1, entries 17-23). After screening a wide range of parameters for indole 1a, we determined the optimized conditions: Pd$\left(\mathrm{OCOCF}_{3}\right)_{2} /(R)-\mathrm{H} 8-\mathrm{BINAP} / \mathrm{L}-\mathrm{CSA} / \mathrm{rt} / \mathrm{TFE}: \mathrm{DCM}=1: 1$.
Table 1. Optimization of Conditions for Asymmetric Hydrogenation of 2-Substituted Indole $1 \mathrm{a}^{a}$

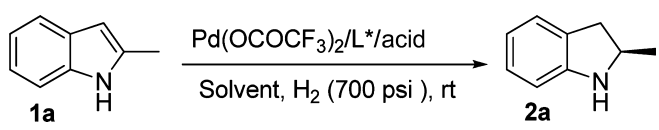

\begin{tabular}{|c|c|c|c|c|c|}
\hline entry & ligand & solvent & acid & $\begin{array}{l}\text { conv } \\
(\%)^{b}\end{array}$ & ee $(\%)^{c}$ \\
\hline 1 & L1 & TFE & - & $<5$ & - \\
\hline 2 & L1 & TFE & $\mathrm{TfOH}$ & 61 & $54(R)$ \\
\hline 3 & L1 & TFE & $\mathrm{PhSO}_{3} \mathrm{H}$ & $>95$ & $62(R)$ \\
\hline 4 & L1 & TFE & $\mathrm{TsOH} \cdot \mathrm{H}_{2} \mathrm{O}$ & $>95$ & $69(R)$ \\
\hline 5 & L1 & TFE & TFA & $>95$ & $8(R)$ \\
\hline 6 & L1 & TFE & L-CSA & $>95$ & $71(R)$ \\
\hline 7 & L1 & TFE & D-CSA & 44 & $66(R)$ \\
\hline 8 & L1 & TFE & $\mathrm{PhCO}_{2} \mathrm{H}$ & $<5$ & $25(R)$ \\
\hline 9 & L1 & TFE & salicylic acid & 35 & $4(R)$ \\
\hline 10 & L1 & $\mathrm{MeOH}$ & L-CSA & 19 & $40(R)$ \\
\hline 11 & L1 & toluene & L-CSA & 57 & $57(R)$ \\
\hline 12 & L1 & THF & L-CSA & $<5$ & - \\
\hline 13 & L1 & DCM & L-CSA & 89 & $73(R)$ \\
\hline 14 & L1 & $\mathrm{DCM} / \mathrm{TFE}(2: 1)$ & L-CSA & $>95$ & $82(R)$ \\
\hline 15 & $\mathbf{L 1}$ & DCM/TFE (1:1) & L-CSA & $>95$ & $85(R)$ \\
\hline 16 & L1 & DCM/TFE (1:2) & L-CSA & $>95$ & $80(R)$ \\
\hline 17 & L2 & DCM/TFE (1:1) & L-CSA & $>95$ & $86(R)$ \\
\hline 18 & L3 & DCM/TFE (1:1) & L-CSA & $>95$ & $81(R)$ \\
\hline 19 & L4 & DCM/TFE (1:1) & L-CSA & $>95$ & $84(R)$ \\
\hline 20 & L5 & DCM/TFE (1:1) & L-CSA & $>95$ & $84(R)$ \\
\hline 21 & L6 & DCM/TFE (1:1) & L-CSA & $>95$ & $91(R)$ \\
\hline 22 & L7 & DCM/TFE (1:1) & L-CSA & 49 & $80(R)$ \\
\hline 23 & L8 & DCM/TFE (1:1) & L-CSA & $<5$ & - \\
\hline & hos L & Phos L2 & $1-5$ & $(R)-\mathrm{C} 4$ & os L4 \\
\hline
\end{tabular}

${ }^{a}$ Conditions: indole 1a $(0.25 \mathrm{mmol})$, acid $(0.25 \mathrm{mmol})$, Pd$\left(\mathrm{OCOCF}_{3}\right)_{2}(2 \mathrm{~mol} \%)$, ligand $(2.4 \mathrm{~mol} \%)$, solvent $(3.0 \mathrm{~mL}), 24 \mathrm{~h}$, rt. ${ }^{b}$ Determined by ${ }^{1} \mathrm{H}$ NMR. ${ }^{c}$ Determined by HPLC.

With the optimized conditions in hand, we investigated the range of substrates (Table 2). Those substrates bearing primary or secondary alkyl groups could all give excellent ee values and moderate to excellent yields. The length of 2 -alkyl substituent as well as the size of the cyclic alkyl substituent had little effect on the enantioselectivities (Table 2, entries 1-5). 2-Phenethyland 2-benzylindole could also give prominent ee values, 93\% and 95\%, respectively (Table 2, entries 6 and 7). The steric effect of benzene ring bearing on benzyl displayed little concern with activities and enantioselectivities (Table 2, entries 8-11). $\gamma$-Ester group was tolerated and high ee was obtained with the slight modification of the reaction conditions (Table 2, entry 12 ), but hydroxyl was not so fortunate (Table 2, entry 13). However, the presence of group at $\mathrm{C} 5$ of indole, such as 5fluoro and 5-methyl, decreased the ee values to $88 \%$ and $84 \%$, respectively (Table 2, entries 14 and 15 ). Unfortunately, 2carbalkoxy and 2-styryl group inhibited the reaction, and the 
Table 2. Pd-Catalyzed Asymmetric Hydrogenation of 2Substituted Indoles $1^{a}$

\begin{tabular}{|c|c|c|c|c|}
\hline entry & $\mathrm{R}^{1}$ & $\mathrm{R}^{2}$ & yield $(\%)^{b}$ & ee $(\%)^{c}$ \\
\hline 1 & $\mathrm{H}$ & $\mathrm{Me}$ & $88(2 a)$ & $91(R)$ \\
\hline 2 & $\mathrm{H}$ & $n-\mathrm{Bu}$ & $82(2 b)$ & $93(R)$ \\
\hline 3 & $\mathrm{H}$ & $n$-pentyl & $89(2 c)$ & $92(R)$ \\
\hline 4 & $\mathrm{H}$ & Cy & $90(\mathbf{2 d})$ & $95(S)$ \\
\hline 5 & $\mathrm{H}$ & cyclopentyl & $85(\mathbf{2 e})$ & $95(S)$ \\
\hline 6 & $\mathrm{H}$ & phenethyl & $89(\mathbf{2 f})$ & $93(R)$ \\
\hline 7 & $\mathrm{H}$ & $\mathrm{Bn}$ & $99(2 \mathrm{~g})$ & $95(R)$ \\
\hline 8 & $\mathrm{H}$ & 2- $\mathrm{MeC}_{6} \mathrm{H}_{4} \mathrm{CH}_{2}$ & $84(2 h)$ & $94(R)$ \\
\hline 9 & $\mathrm{H}$ & $3-\mathrm{MeC}_{6} \mathrm{H}_{4} \mathrm{CH}_{2}$ & $95(2 \mathrm{i})$ & $94(R)$ \\
\hline 10 & $\mathrm{H}$ & 4- $\mathrm{MeC}_{6} \mathrm{H}_{4} \mathrm{CH}_{2}$ & $82(2 \mathbf{j})$ & $93(R)$ \\
\hline 11 & $\mathrm{H}$ & 1-naphthyl- $\mathrm{CH}_{2}$ & $78(2 \mathbf{k})$ & $96(R)$ \\
\hline $12^{d}$ & $\mathrm{H}$ & $\mathrm{CH}_{2} \mathrm{CH}_{2} \mathrm{COOEt}$ & $98(2 \mathrm{l})$ & $84(R)$ \\
\hline 13 & $\mathrm{H}$ & $\mathrm{CH}_{2} \mathrm{CH}_{2} \mathrm{CH}_{2} \mathrm{OH}$ & $<5$ & - \\
\hline 14 & $5-\mathrm{F}$ & $\mathrm{Me}$ & $84(2 \mathrm{~m})$ & $88(R)$ \\
\hline 15 & 5-Me & $\mathrm{Me}$ & $81(2 n)$ & $84(R)$ \\
\hline 16 & $\mathrm{H}$ & COOEt & $<5$ & - \\
\hline 17 & $\mathrm{H}$ & styryl $(E)$ & $<5$ & - \\
\hline 18 & $\mathrm{H}$ & $\mathrm{CF}_{3}$ & $<5$ & - \\
\hline 19 & $\mathrm{H}$ & $t-\mathrm{Bu}$ & $<5$ & - \\
\hline 20 & $\mathrm{H}$ & $\mathrm{Ph}$ & $<5$ & - \\
\hline
\end{tabular}

${ }^{a}$ Conditions: $1(0.25 \mathrm{mmol})$, L-CSA $(0.25 \mathrm{mmol}), \mathrm{Pd}\left(\mathrm{OCOCF}_{3}\right)_{2}(2$ mol\%), (R)-H8-BINAP (2.4 mol\%), DCM/TFE (3 mL, 1:1), 24 h, rt. ${ }^{b}$ Isolated yield. ${ }^{c}$ Determined by HPLC. ${ }^{d} 50{ }^{\circ} \mathrm{C}$.

double bond of the styryl group was intact (Table 2, entries 16 and 17). Meanwhile, sterically more demanding groups (tertbutyl) and electron-withdrawing goups (trifluoromethyl group) were problematic with low activity (Table 2, entries 18 and 19). Disappointingly, almost no reaction was observed when 2phenylindole was subjected to the standard conditions (Table 2, entry 20).

Asymmetric Hydrogenation of Simple 2,3-Disubstituted Indoles. Encouraged by successful asymmetric hydrogenation of unprotected 2-substituted indoles, we next turned our attention to asymmetric hydrogenation of 2,3-disubstituted indoles. Unlike the results with the simple 2-substituted indoles, two contiguous chiral centers will be obtained in the hydrogenation of 2,3-disubstituted indoles. These two chiral carbons are produced in different steps: asymmetric protonation and asymmetric hydrogenation. Initially, the chiral center at the 3-position is generated from protonation of indole 3. Subsequently, selective hydrogenation of one of the isomers gives the hydrogenation product 4 (Scheme 2). Indeed, a classical dynamic kinetic asymmetric transformation process is involved in this reaction.

Accordingly, to obtain enantiomerically pure products, the protonation step should be much faster than the hydrogenation step $\left(k_{1} \gg k_{2}\right)$. A higher reaction temperature should accelerate the protonation step, and a lower pressure of hydrogen gas should decrease the rate of hydrogenation of the iminium intermediate. Based on the theoretical analysis, a higher temperature as well as a lower pressure of hydrogen gas might guarantee the success of this process.

Thus, the reaction temperature of hydrogenation was increased to $50{ }^{\circ} \mathrm{C}$ for further reaction optimization. Initial solvent screening showed that the mixed solvent DCM/TFE
Scheme 2. Asymmetric Hydrogenation of 2,3-Disubstituted Indoles 3 via a Dynamic Kinetic Resolution Process

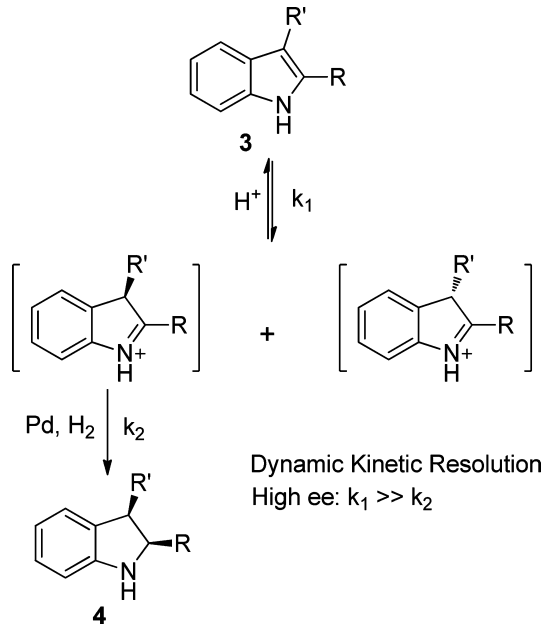

(2:1) gave better results than the others (Table 3, entry 3 vs entries 1 and 2), yielding only the cis-2,3-disubstituted indoline

Table 3. Optimization for Asymmetric Hydrogenation of 2,3-Disubstituted Indole $3 \mathrm{a}^{a}$

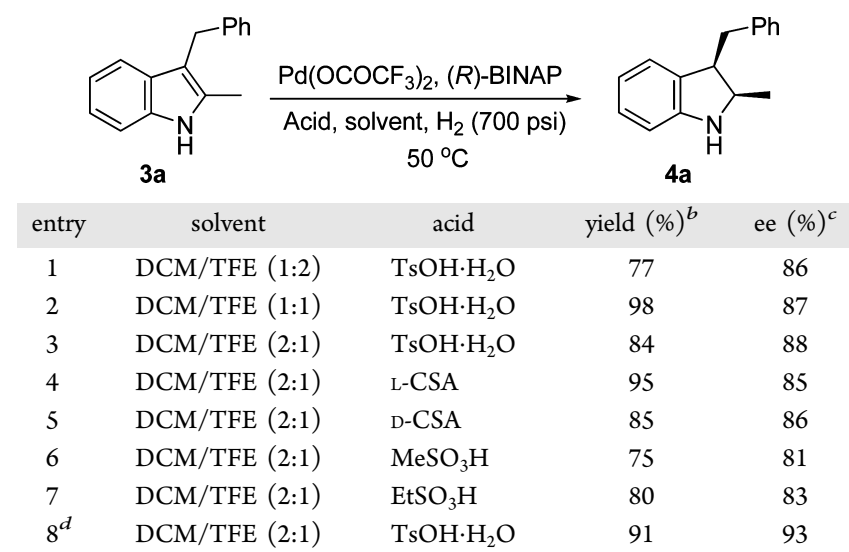

${ }^{a}$ Conditions: indole $3 \mathrm{a}(0.25 \mathrm{mmol})$, acid $(0.25 \mathrm{mmol})$, Pd$\left(\mathrm{OCOCF}_{3}\right)_{2}(2 \mathrm{~mol} \%),(R)$-BINAP $(2.4 \mathrm{~mol} \%)$, solvent $(3.0 \mathrm{~mL})$, $24 \mathrm{~h}, 50{ }^{\circ} \mathrm{C} .{ }^{b}$ Isolated yield. ${ }^{c}$ Determined by HPLC. ${ }^{d}(R)$-H8-BINAP was used as the ligand.

isomer. A survey of sulfonic acids indicated that $p$ toluenesulfonic acid $\left(\mathrm{TsOH} \cdot \mathrm{H}_{2} \mathrm{O}\right)$ was the best choice (Table 3 , entry 3 vs entries $4-7$ ). The ee value was enhanced to $93 \%$ (Table 3, entry 8) when asymmetric hydrogenation was performed with (R)-H8-BINAP as ligand. Therefore, the optimized reaction conditions are as follows: $\mathrm{Pd}\left(\mathrm{OCOCF}_{3}\right)_{2} /$ (R)-H8-BINAP/TsOH $\cdot \mathrm{H}_{2} \mathrm{O} / \mathrm{DCM}: \mathrm{TFE}=2: 1$ at $50{ }^{\circ} \mathrm{C}$.

Under the optimized conditions, a variety of 2,3-disustituted indoles were subjected to asymmetric hydrogenation, and excellent enantioselectivities and diastereoselectivities were obtained (Table 4). 3-Benzyl-substituted indoles were slightly inferior to 3-alkyl-substituted indoles in terms of ee for this asymmetric hydrogenation (Table 4 , entries $1-3$ vs entries 4 and 5). The introduction of electron-donating and electronwithdrawing groups on the phenyl ring of 3-benzyl was found to not affect the reaction significantly (Table 4 , entry 2 vs entry 3). To ensure the high enantioselectivity of indolines 4, a slight modification was made, such as reducing the hydrogen pressure 
Table 4. Asymmetric Hydrogenation of 2,3-Disubstituted Indoles $3^{a}$
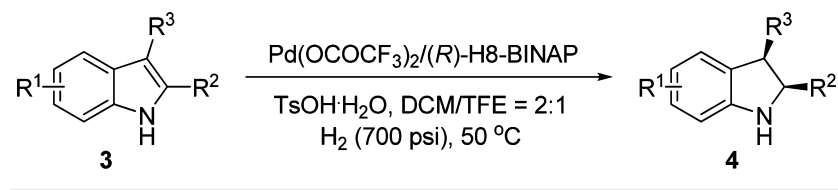

\begin{tabular}{|c|c|c|c|c|}
\hline entry & $\mathrm{R}^{1}$ & $\mathrm{R}^{2} / \mathrm{R}^{3}$ & yield $(\%)^{b}$ & ee $(\%)^{c}$ \\
\hline 1 & $\mathrm{H}$ & $\mathrm{Me} / \mathrm{Bn}$ & $93(4 a)$ & 91 \\
\hline 2 & $\mathrm{H}$ & $\mathrm{Me} / 4-\mathrm{MeOC}_{6} \mathrm{H}_{4} \mathrm{CH}_{2}$ & $94(4 b)$ & 91 \\
\hline 3 & $\mathrm{H}$ & $\mathrm{Me} / 4-\mathrm{FC}_{6} \mathrm{H}_{4} \mathrm{CH}_{2}$ & $97(4 c)$ & 91 \\
\hline 4 & $\mathrm{H}$ & $\mathrm{Me} / \mathrm{CyCH}_{2}$ & $81(4 d)$ & 94 \\
\hline 5 & $\mathrm{H}$ & $\mathrm{Me} / i-\mathrm{PrCH}_{2}$ & $89(4 e)$ & 94 \\
\hline 6 & $\mathrm{H}$ & phenethyl/Bn & $93(4 f)$ & 94 \\
\hline $7^{d}$ & $\mathrm{H}$ & $-\left(\mathrm{CH}_{2}\right)_{4}-$ & $91(4 \mathrm{~g})$ & $91(R, R)$ \\
\hline $8^{d}$ & $\mathrm{H}$ & $-\left(\mathrm{CH}_{2}\right)_{5}-$ & $96(4 h)$ & $90(R, R)$ \\
\hline $9^{d, e}$ & $\mathrm{H}$ & $\mathrm{Me} / \mathrm{Me}$ & $84(4 \mathbf{i})$ & $92(R, R)$ \\
\hline 10 & $5-\mathrm{F}$ & $\mathrm{Me} / \mathrm{Bn}$ & $93(4 \mathbf{j})$ & 87 \\
\hline 11 & $5-F$ & $\mathrm{Me} / \mathrm{CyCH}_{2}$ & $92(4 k)$ & 92 \\
\hline 12 & 7-Me & $\mathrm{Me} / \mathrm{Bn}$ & $95(41)$ & 97 \\
\hline 13 & 7-Me & $\mathrm{Me} / \mathrm{CyCH}_{2}$ & $87(4 m)$ & 96 \\
\hline 14 & 7-Me & $\mathrm{Me} / 2-\mathrm{MeC}_{6} \mathrm{H}_{4} \mathrm{CH}_{2}$ & $82(4 n)$ & 98 \\
\hline 15 & 7-Me & $\mathrm{Me} / 3-\mathrm{MeC}_{6} \mathrm{H}_{4} \mathrm{CH}_{2}$ & $98(40)$ & 97 \\
\hline 16 & 7-Me & $\mathrm{Me} / 4-\mathrm{MeC}_{6} \mathrm{H}_{4} \mathrm{CH}_{2}$ & $87(4 p)$ & 97 \\
\hline $17^{d, e}$ & 7-Me & $-\left(\mathrm{CH}_{2}\right)_{4}-$ & $83(4 q)$ & $96(R, R)$ \\
\hline 18 & $\mathrm{H}$ & $\mathrm{Me} / \mathrm{CO}_{2} \mathrm{Et}$ & $<5$ & - \\
\hline
\end{tabular}

${ }^{a}$ Conditions: indole $3(0.25 \mathrm{mmol}), \mathrm{TsOH} \cdot \mathrm{H}_{2} \mathrm{O}(0.25 \mathrm{mmol})$, $\mathrm{Pd}\left(\mathrm{OCOCF}_{3}\right)_{2}(2 \mathrm{~mol} \%),(R)$-H8-BINAP (2.4 mol\%), DCM/TFE $(3.0 \mathrm{~mL}, 2: 1), 24 \mathrm{~h}, 50{ }^{\circ} \mathrm{C}$. ${ }^{b}$ Isolated yield. ${ }^{c}$ Determined by HPLC. ${ }^{d}$ Using L-CSA and solvent (DCM/TFE $\left.1: 1\right)$ at rt. ${ }^{e} 50{ }^{\circ} \mathrm{C}$ and $\mathrm{H}_{2}(300$ psi).

(Table 4, entries 9 and 17). We found that ring-fused substrates could also give satisfying results (Table 4, entries 7-9 and 17), and indoles bearing a 5-F substituent displayed slightly lower ee than other indoles (Table 4, entries 10 and 11). 7-Methylsubstituted 2,3-disubstituted indoles showed remarkable enantioselectivities (96-98\% ee, Table 4, entries 12-17). Unfortunately, 3-carbalkoxy-2-methylindole 3r could not be hydrogenated under the standard conditions (Table 4, entry 18).

Asymmetric Hydrogenation of $\mathrm{N}$-Protected Indoles. $\mathrm{N}$-Protected indoles were also subjected to hydrogenation under the above standard conditions (Scheme 3). Unfortunately, it was found that these substrates were not good partners for Pd catalyst system. The low enantioselectivity might be due to that fact that the protecting groups on the $N$ atom prevent the generation of an iminium intermediate and/ or inhibit hydrogen-bonding interaction with the trifluoroace-

Scheme 3. Asymmetric Hydrogenation of $\mathrm{N}$-Protected Indoles
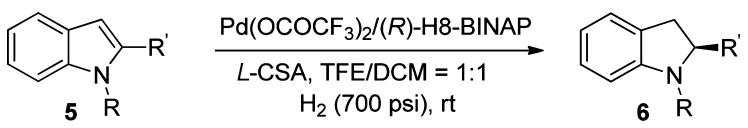

$\mathrm{R}=\mathrm{Bn}, \mathrm{Me}, \mathrm{Boc}, \mathrm{Ts}$,

Poor ee or poor activity

\begin{tabular}{c|ccc} 
Entry & $\mathrm{R}$ & Yield (\%) & Ee (\%) \\
\hline 1 & $\mathrm{Bn}$ & 92 & 0 \\
2 & $\mathrm{Me}$ & 40 & 38 \\
3 & $\mathrm{Ph}$ & 5 & - \\
4 & $\mathrm{Boc}$ & - & -
\end{tabular}

tate coordinated on the $\mathrm{Pd}$ catalyst. These two points are crucial for Pd-catalyzed asymmetric hydrogenation of unprotected indoles (for details, see the Mechanistic Study section).

Product Elaboration. To demonstrate the utility of $\mathrm{Pd}$ catalyzed asymmetric hydrogenation of the unprotected indoles, a direct and efficient method was developed to synthesize the enantiopure indoline skeleton derivative $\mathbf{8}$, an neuroleptic agent in many types of antidepressants. ${ }^{23}$ As shown in Scheme 4, asymmetric hydrogenation of 2,3-disubstituted

Scheme 4. Synthesis of Biologically Active Product 8

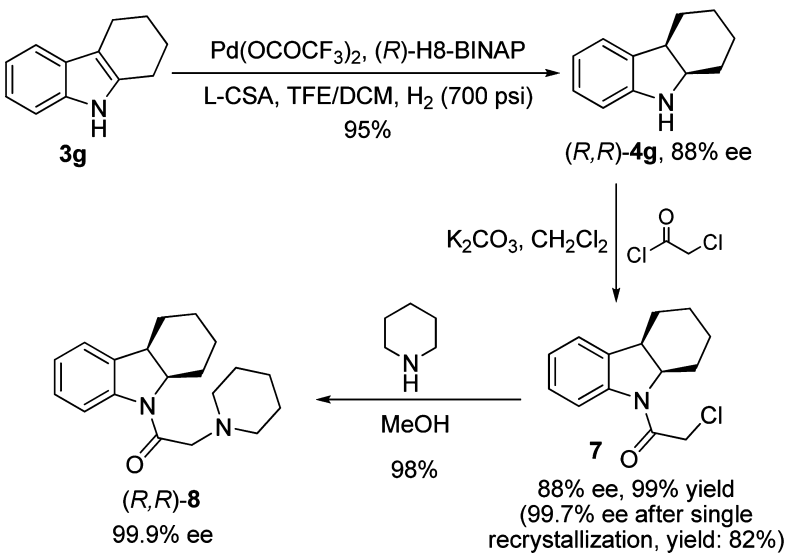

indole $3 \mathrm{~g}$ gave the key intermediate hexahydrocarbazole $\mathbf{4 g}$ with $88 \%$ ee. Subsequent protection with 2-chloroacetyl chloride and a simple recrystallization afforded the intermediate 7 with $99 \%$ ee. Finally, $N$-alkylation gave the biologically active compound 8 in high overall yields and up to $99.9 \%$ ee.

\section{MECHANISTIC STUDY}

Iminium Intermediate. Iminium and vinylogous iminium have been found to be significant intermediates in numerous organic reactions, ${ }^{24}$ and they are also cucial for the success of the asymmetric hydrogenation of unprotected indoles.

Further confirmation of the presence of the iminium in the hydrogenation reaction is required; therefore, iminium salt was conveniently prepared with the equivalent 2-methylindole and $\mathrm{TsOH} \cdot \mathrm{H}_{2} \mathrm{O}$ in $\mathrm{CDCl}_{3}$ after stirring $5 \mathrm{~min}$ at room temperature. ${ }^{1} \mathrm{H}$ NMR investigation indicated that the signal of the hydrogen at the 3-position became broad and shifted upfield, and the $\mathrm{N}-$ $\mathrm{H}$ peak disappeared rapidly. When $\mathrm{TsOH} \cdot \mathrm{H}_{2} \mathrm{O}$ was exchanged with $\mathrm{D}_{2} \mathrm{O}$ before being applied to this system, all the peaks from the ${ }^{1} \mathrm{H}$ NMR study in $\mathrm{CDCl}_{3}$ remained the same as before, except for the partial disappearance of the $3-\mathrm{H}$ of iminium (Figure 1). Subsequent electrospray ionization mass spectroscopic analysis of a similar solution showed peaks at $\mathrm{m} /$ $z^{+} 132.0833$ and $m / z^{-} 171.0083$, which agreed with the ion pair of the iminium intermediate (eq 1). In this way, the iminium salt generated before hydrogenation was identified.

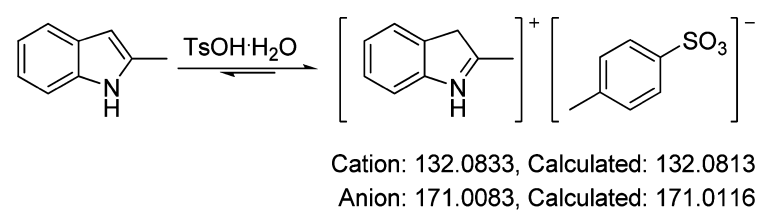




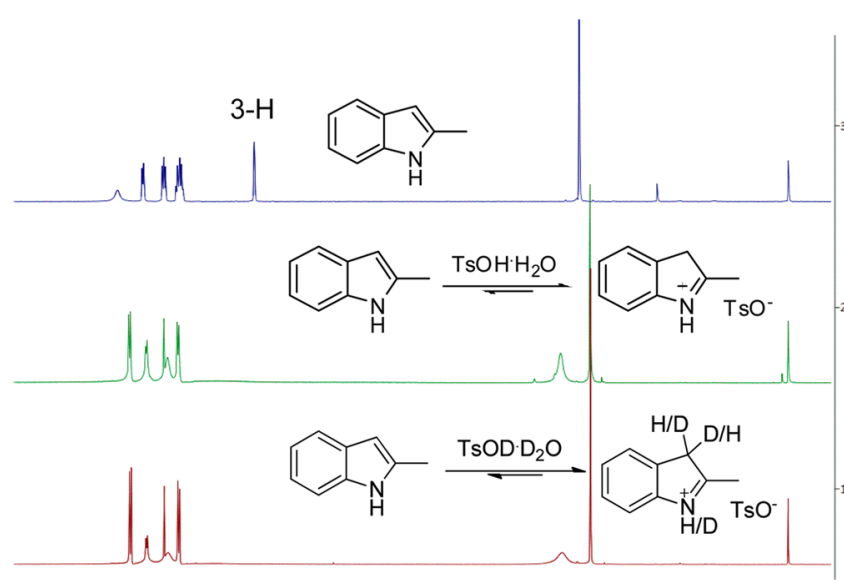

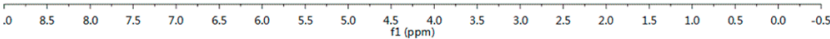

Figure 1. ${ }^{1} \mathrm{H}$ NMR study of $\mathrm{TsOH} \cdot \mathrm{H}_{2} \mathrm{O}$ or $\mathrm{TsOD} \cdot \mathrm{D}_{2} \mathrm{O}$ as well as 2methylindole in $\mathrm{CDCl}_{3}$.

Isotopic labeling experiments using deuterated solvent and deuterium gas also affirmed the above conclusion (eqs 2 and 3 ).

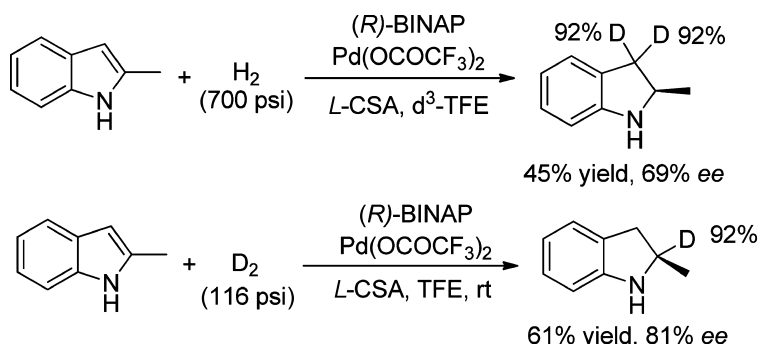

The first step was generation of the iminium intermediate, and then this active iminium intermediate was hydrogenated to afford the desired product. When the asymmetric hydrogenation was run in deuterated TFE, ${ }^{1} \mathrm{H}$ NMR analysis of the crude products showed that two deuterium atoms were incorporated at the 3-position of 2-methylindoline (eq 2), which suggested a fast, reversible process of protonation and deprotonation. Thus, two deuterium atoms were incorporated at the 3-position before hydrogenation. When 2-methylindole was subjected to hydrogenation with $\mathrm{D}_{2}$, 2-deuterio-2methylindoline with $92 \%$ incorporation was obtained without deuterium at the 3-position (eq 3). The above experimental results suggested that the simple unprotected indoles can be activated by a Brønsted acid to form iminium in situ, which can then be hydrogenated by the chiral Pd catalyst.

Active Pd Hydride Species. Metal hydride active species have been involved not only in hydrogenation but also in many other organic reactions as the key intermediate. However, several factors impede the thorough study of the metal hydride intermediates. ${ }^{25}$ Generally, the metal hydrides are generated in the reaction in only trace amounts, and the metal hydrides are unstable in many conditions. Therefore, it is challenging to isolate them and determine their conformations or properties. ${ }^{26}$ Given the importance of metal hydrides in such reactions, especially in hydrogenation reactions, here we present the most likely paths to generate $\mathrm{Pd}-\mathrm{H}$ in the $\mathrm{Pd}$-catalyzed asymmetric hydrogenation, based on our experience.

As can be seen from Scheme 5 and Figure 2, in path A, first, protonation of one $\mathrm{CF}_{3} \mathrm{COO}^{-}$ligand by strong acid $\mathrm{TsOH}$ gives INT A1, and then the $\mathrm{CF}_{3} \mathrm{COOH}$ ligand is detached from the Pd catalyst to generate an unoccupied site, INT A2. $\mathrm{H}_{2}$ combines with this active center (INT A3) and is activated with

Scheme 5. Proposed Pathways for Reaction of Hydrogen Gas and Pd Catalyst To Generate Pd-H Species

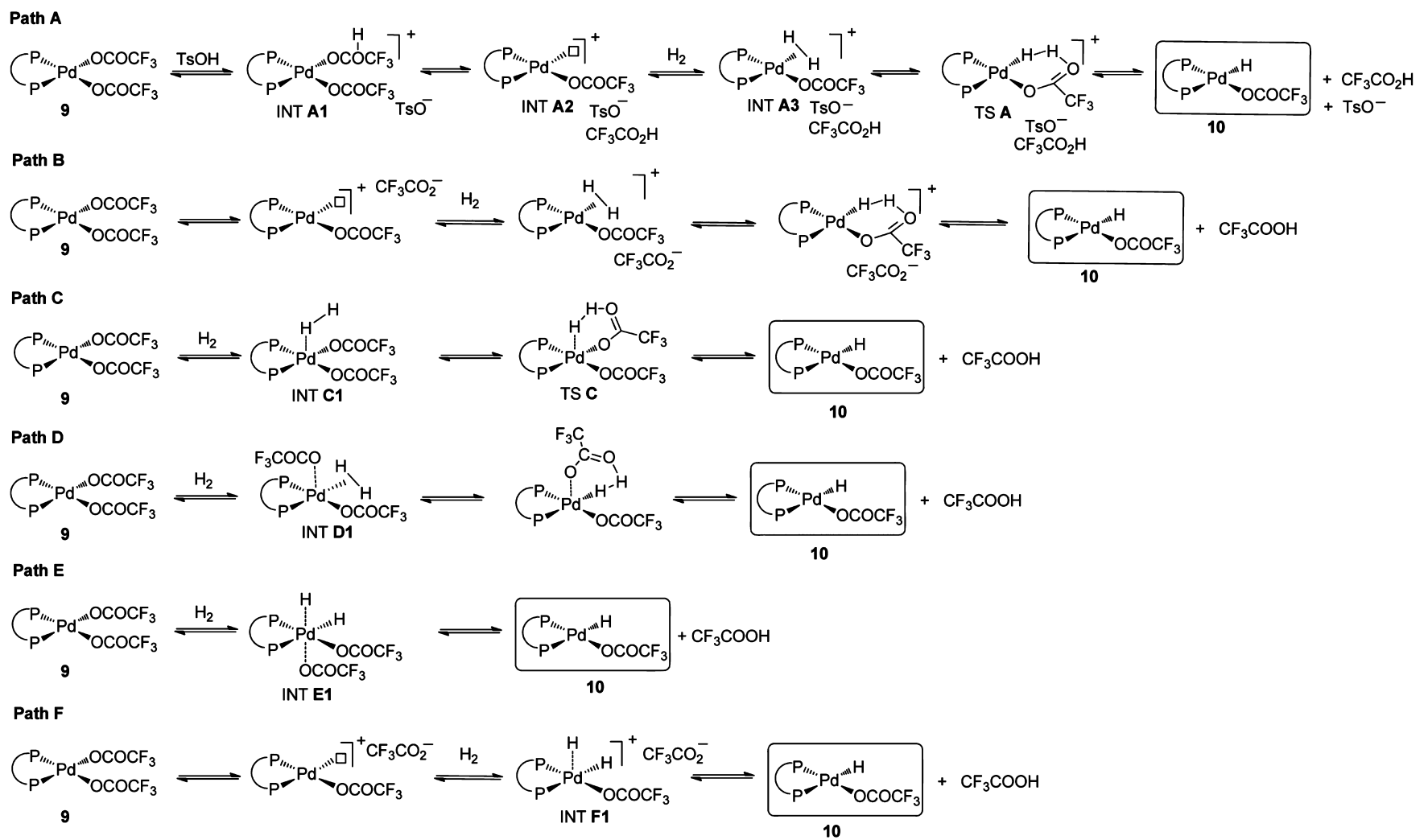




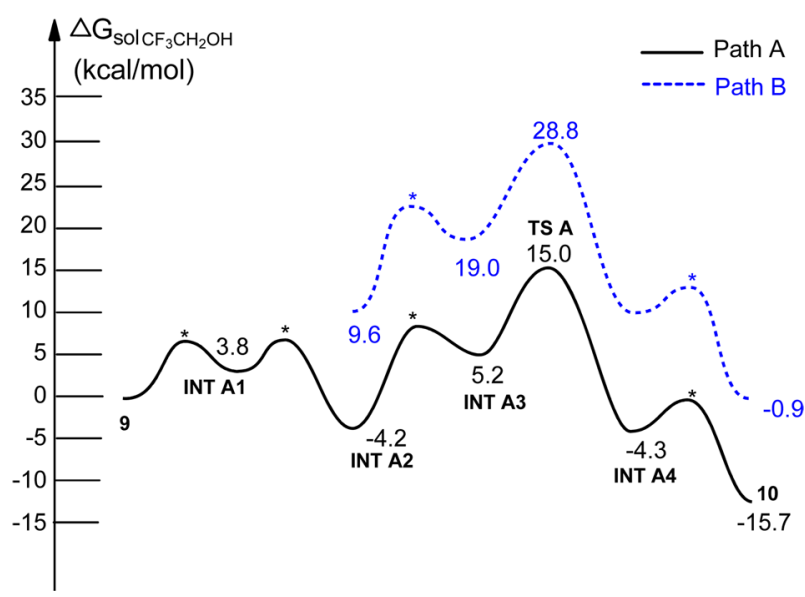

Figure 2. Computed reaction energy profiles for path A (with the help of $\mathrm{TsOH}$ ) and path B (strong acid is not involved) to generate palladium hydride in TFE. Relative energies in $\mathrm{kcal} / \mathrm{mol}$ are given.

assistance from $\mathrm{Pd}$ and the coordinated $\mathrm{CF}_{3} \mathrm{COO}^{-}$ligand (TS A). The last step is the ligand exchange (or proton exchange) between $\mathrm{CF}_{3} \mathrm{COO}^{-}$and the coordinated $\mathrm{CF}_{3} \mathrm{COOH}$ (INT A4) to offer the $\mathrm{Pd}-\mathrm{H}$ species 10. In path $\mathrm{B}$, one $\mathrm{CF}_{3} \mathrm{COO}^{-}$ligand is directly detached from the $\mathrm{Pd}$ catalyst to generate an unoccupied site, INT A2. The following steps are the same as in path $\mathrm{A}$. In path $\mathrm{C}, \mathrm{H}_{2}$ coordinates to $\mathrm{Pd}$ catalyst first (INT C1) and then is activated by $\mathrm{Pd}$ and a $\mathrm{CF}_{3} \mathrm{COO}^{-}$ligand. $\mathrm{Pd}-\mathrm{H}$ species 10 is generated with the remaining coordinated $\mathrm{CF}_{3} \mathrm{COOH}$. Path $\mathrm{D}$ is similar to path $\mathrm{C}$, except that $\mathrm{CF}_{3} \mathrm{COO}^{-}$is on the apical position in INT D1, while $\mathrm{H}_{2}$ is on the apical position in INT C1. $\mathrm{H}_{2}$ is activated by $\mathrm{Pd}$ and a $\mathrm{CF}_{3} \mathrm{COO}^{-}$ligand. In path $\mathrm{E}, \mathrm{H}_{2}$ is activated by the $\mathrm{Pd}$ catalyst through oxidative addition, followed by reductive elimination of $\mathrm{CF}_{3} \mathrm{COOH}$ to generate the $\mathrm{Pd}-\mathrm{H}$ species 10 . In path $\mathrm{F}$, the first step is similar to that in path $\mathrm{B}$, but $\mathrm{H}_{2}$ is activated by the unsaturated $\mathrm{Pd}$ catalyst center through oxidative addition. Finally, the $\mathrm{Pd}-\mathrm{H}$ species is generated after release of $\mathrm{CF}_{3} \mathrm{COOH}$. Paths $\mathrm{A}, \mathrm{B}$, and $\mathrm{F}$ are ionic pathways, while paths $\mathrm{C}, \mathrm{D}$, and $\mathrm{E}$ are not. Paths $\mathrm{C}$ and $\mathrm{D}$ may suffer due to the five-coordinated TS C, INT C1, and INT D1, which are not common for transition metals with $\mathrm{d}^{8}$ configuration. Paths $\mathrm{E}$ and $\mathrm{F}$ may suffer due to the oxidative addition, since $\mathrm{H}_{2}$ may not be able to oxidize $\mathrm{Pd}(\mathrm{II})$ to $\mathrm{Pd}(\mathrm{IV})$.

DFT calculations were carried out to elucidate which is the most facile path, ${ }^{27}$ using TFE as the solvent (B3LYP; for details, see Supporting Information). First, the rate-determining barrier of path C is $32.9 \mathrm{kcal} / \mathrm{mol}$. The energies of INT D1 $(30.3 \mathrm{kcal} / \mathrm{mol})$, INT E1 $(46.6 \mathrm{kcal} / \mathrm{mol})$, and INT F1 $(44.8$ $\mathrm{kcal} / \mathrm{mol}$ ) were found to be too high. Therefore, paths $\mathrm{C}-\mathrm{F}$ were ruled out. All rate-determining barriers mentioned in this section were relative to the most stable structure prior to the rate-determining step, which means INT A2 for path A and reactant $\mathrm{Pd}$ catalyst 9 for all other paths. The reaction profiles of paths A and B are shown in Figure 2. We found that path A is preferred, with the rate-determining barrier of $19.2 \mathrm{kcal} / \mathrm{mol}$. Protonation of the Pd catalyst by $\mathrm{TsOH}$ requires $3.8 \mathrm{kcal} / \mathrm{mol}$. Releasing the $\mathrm{CF}_{3} \mathrm{COOH}$ ligand gains $8.0 \mathrm{kcal} / \mathrm{mol}$ and offers an unoccupied site on $\mathrm{Pd}$ ion, which facilitates the $\mathrm{H}_{2}$ coordination and activation. The $\mathrm{H}_{2}$ activation step is the rate-determining step. The barrier of path $\mathrm{B}$ is higher than that of path A by $13.8 \mathrm{kcal} / \operatorname{mol}\left(\Delta G_{\mathrm{TS}}\right.$ B $\left.-\Delta G_{\mathrm{TS}}\right)$, which arises from the thermodynamic stability difference between $\mathrm{TsO}^{-}$and
$\mathrm{CF}_{3} \mathrm{COO}^{-}$. The transition states marked with * in Figure 2 are for the ligand coordination or detachment steps. Harvey has recently suggested that such processes correspond to diffusion control, ${ }^{28}$ with free energy barriers of ca. $4.5 \mathrm{kcal} / \mathrm{mol}$, and are not expected to be competitive with the rate-determining barriers. The key transition state TS A is shown in Figure 3. It is

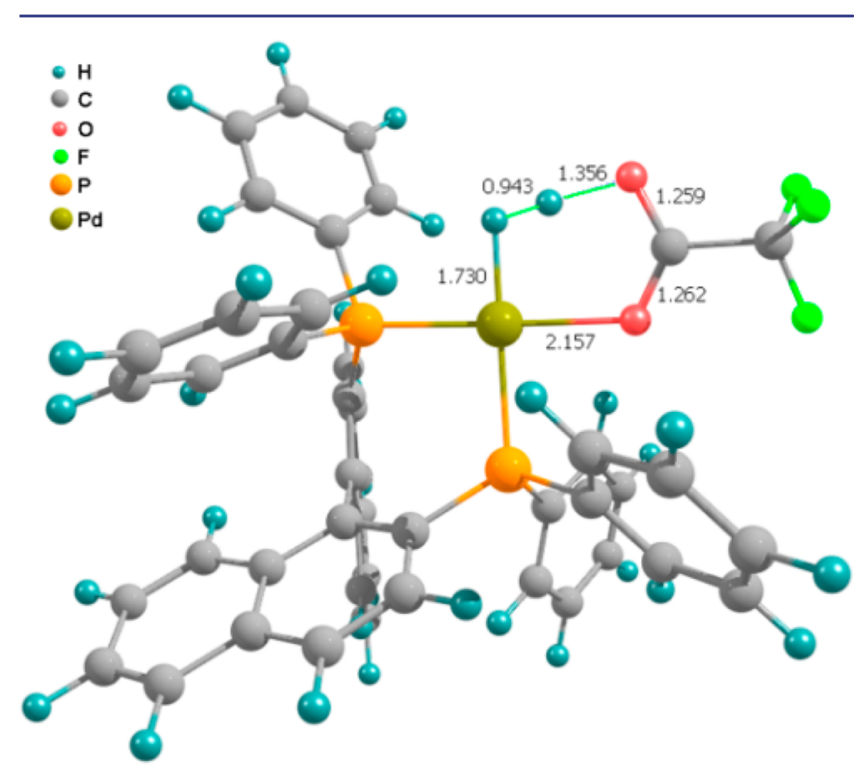

Figure 3. Computed structure of TS A. Bond lengths are given in $\AA$.

an earlier transition state $(\mathrm{H}-\mathrm{H}=0.94 \AA$ in TS A) with squareplanar structure as one would expect for $\mathrm{d}^{8}$ transition metals. The transition state (TS C) of the non-ionic path C is shown in Figure 4. It has a square-pyramid structure, with the weakly coordinated $\mathrm{CF}_{3} \mathrm{COO}^{-}(\mathrm{Pd}-\mathrm{O}=2.52 \AA)$ on the apical position.

Toward lifting the veil of active $\mathrm{Pd}-\mathrm{H},{ }^{1} \mathrm{H}$ NMR was at the top of our list. As to the equilibrium between Pd catalyst and $\mathrm{Pd}-\mathrm{H}$ species (Scheme 6), the low concentration of $\mathrm{Pd}-\mathrm{H}$ met our expectation, but also made it difficult to study. Under

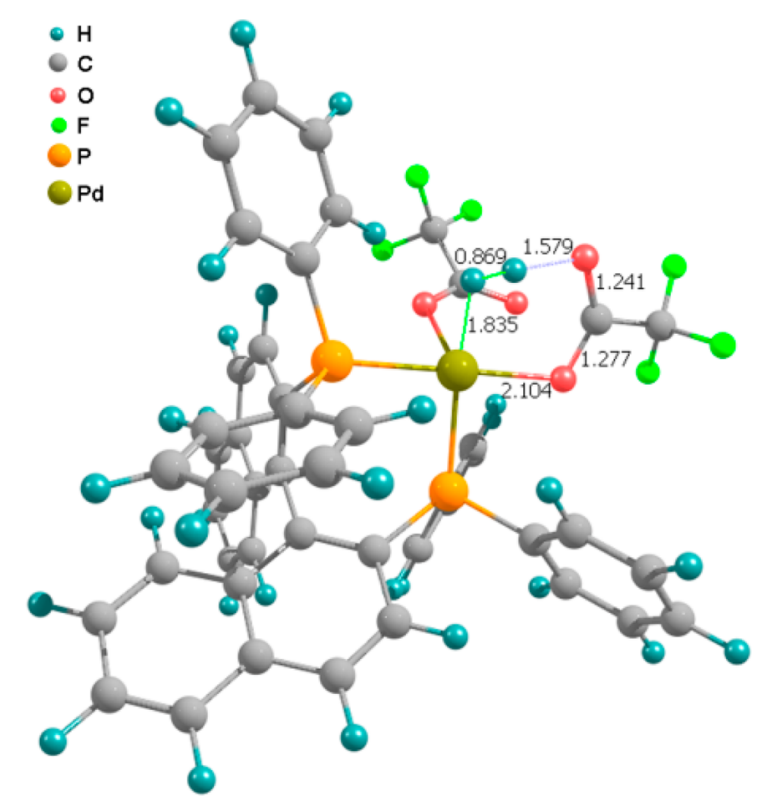

Figure 4. Computed structure of TS C. Bond lengths are given in $\AA$. 
Scheme 6. Generation and ${ }^{1} \mathrm{H}$ NMR Spectrum of $\mathrm{Pd}-\mathrm{H}$

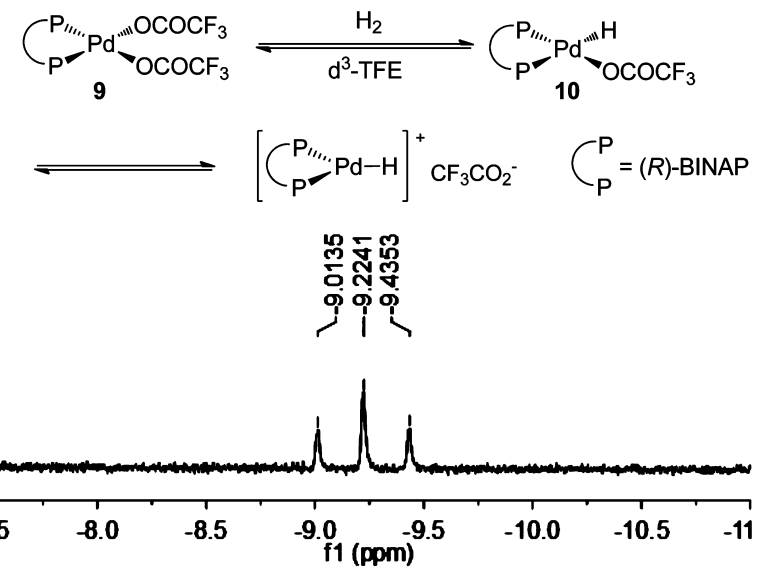

rigidly controlled conditions, fortunately, some proofs were obtained. A diagnostic virtual triplet in the ${ }^{1} \mathrm{H}$ NMR spectrum at $-9.22 \mathrm{ppm}(J=84.4 \mathrm{~Hz})$ (Scheme 6) and the chemical shift were consistent with most of the metal hydrides reported. ${ }^{26}$ Since th coupling constant was between those of hydrogen coupling with cis-phosphorus $(J=5-16 \mathrm{~Hz})$ and hydrogen coupling with trans-phosphorus $(J \approx 160 \mathrm{~Hz})$, it was inferred that the hydrogen in $\mathrm{Pd}-\mathrm{H}$ couples with phosphorus with an angle between the cis and trans positions. This could be ascribed to equilibrium between the reversible reductive elimination of TFA and some other intermediates (Scheme 6). Also, an interesting phenomenon was observed in studying $\mathrm{Pd}-\mathrm{H}$ species. When the chiral palladium catalyst [Pd$\left.\left(\mathrm{OCOCF}_{3}\right)_{2}(R)-\mathrm{BINAP}\right]$ was put in the TFE, the solution was yellow. After being subjected to hydrogen gas, the solution turned from yellow to red, and deep red about 15 min later. This color does not fade over time or upon subjecting the solution to oxygen.

Robustness of Pd Catalyst to Air and Water. In the process of running experiments, we found that the chiral Pdcatalyzed asymmetric hydrogenation is relatively robust to air, acid, and water. In order to study this issue further, several controlled experiments were designed, as shown in Scheme 7

Scheme 7. Controlled Experiments on the Influence of Air and $\mathrm{H}_{2} \mathrm{O}$
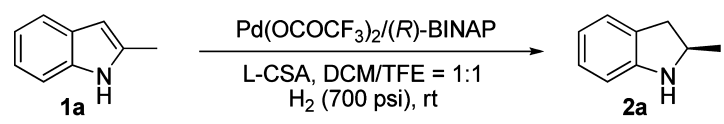

\begin{tabular}{c|ccc} 
Entry & Condition & Conv. (\%) & Ee (\%) \\
\hline 1 & $\mathrm{~N}_{2}$ & $>95$ & 81 \\
2 & Air & $>95$ & 81 \\
3 & Air, $\mathrm{H}_{2} \mathrm{O}$ (4 eq.) & $>95$ & 80
\end{tabular}

(Table 1 , entry 18 is equal to Scheme 7 , entry 1 ). First, we performed the hydrogenation in the atmosphere without the Schlenk technique (Scheme 7 , entry 2); i.e., the catalyst was prepared in the air and the substrate, Brønsted acid, solvent, and the catalyst were also mixed in the air. The experimental results confirmed our deduction that the hydrogenation went on well with similar activity and enantioselectivity (Scheme 7, entry 1 vs entry 2 ). Second, we added water to the reaction solution (Scheme 7, entry 3). No difference was noticed until 4 equiv of water relative to substrate was added to the reaction
(Scheme 7, entry 1 vs entry 3 ). The results of these experiments suggest that chiral the Pd catalyst has a relatively impassive behavior to air and water. To explain this, we proposed that the $\mathrm{Pd}-\mathrm{H}$ generated from $\mathrm{Pd}\left(\mathrm{OCOCF}_{3}\right)_{2}$ under $\mathrm{H}_{2}$ atmosphere could be oxidized to hydrogen peroxide or water and $\mathrm{Pd}(\mathrm{II})$ by oxygen in the presence of trifluoroacetic acid (Scheme 8), which has been reported by Sigman and

Scheme 8. Proposed Reasons for the Stability of Pd Catalyst to $\mathrm{O}_{2}$

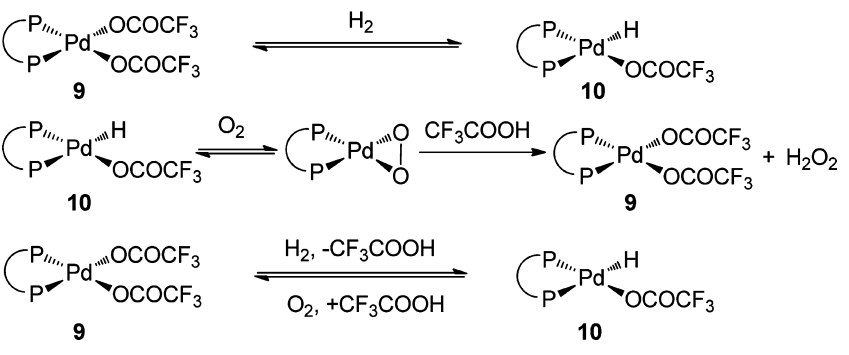

Stahl. ${ }^{25 f, g, i-k}$ But it was not ruled out that the $\mathrm{Pd}-\mathrm{H}$ complex is simply unreactive toward $\mathrm{O}_{2}$. Actually, the formed $\mathrm{Pd}(\mathrm{II})$ species is our hydrogenation catalyst precursor, so the $\mathrm{Pd}-\mathrm{H}$ can be regenerated. Therefore, the $\mathrm{Pd}$ catalyst is relatively insensitive to air, acid, and water.

Roles of Solvent Trifluoroethanol. Fluorinated alcohols, especially hexafluoroisopropanol (HFIP) and TFE, are used as solvents, cosolvents, and additives in many reactions, given their unique properties. ${ }^{29}$ These properties, which made fluorinated alcohols a range of robust solvents, were usually considered to be high hydrogen bond donor ability, low nucleophilicity, high ionizing power, ability to solvate water, and so on. TFE, as one of the inexpensive fluorinated alcohols, has been commonly applied in synthetic chemistry.

Recently, asymmetric hydrogenation has gained much interest because of its superb ability to construct chiral compounds. Our group contributed many examples to this thriving area. When we reviewed these hydrogenation reactions, an interesting phenomenon was noticed: excellent enantioselectivity and high activity are generally obtained in TFE in the Pd-catalyzed asymmetric hydrogenations. According to the literature and our experiences, two conclusions might be drawn: (1) TFE participates in the formation of some key intermediates, ${ }^{30}$ or (2) TFE stabilizes these intermediates. As can be seen from Scheme 9, TFE participated in the exchange

Scheme 9. Exchange of the Counterion of Pd-H Complex and TFE

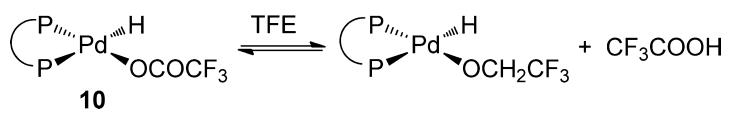

of the counterion of the $\mathrm{Pd}$ catalyst before or after the formation of $\mathrm{Pd}-\mathrm{H}$ complex. Since $\mathrm{CF}_{3} \mathrm{CH}_{2} \mathrm{O}^{-}$is more nucleophilic than $\mathrm{CF}_{3} \mathrm{COO}^{-}$, this exchange seemed reasonable. But when we subjected the Pd catalyst to $\mathrm{H}_{2}$ in TFE, followed by in situ IR, we found there is barely a peak at $1790 \mathrm{~cm}^{-1}$, which is the characteristic peak of the carbonyl group of $\mathrm{CF}_{3} \mathrm{COOH}$.

The role of TFE has also been studied theoretically. First we studied whether TFE was involved in the reaction directly by replacing one $\mathrm{CF}_{3} \mathrm{COO}^{-}$with $\mathrm{CF}_{3} \mathrm{CH}_{2} \mathrm{O}^{-}$. We only considered 
Scheme 10. Possible TFE-Participating Pathway for Reaction of $\mathbf{H}_{2}$ and Pd Catalyst To Generate Pd-H Species

Path G

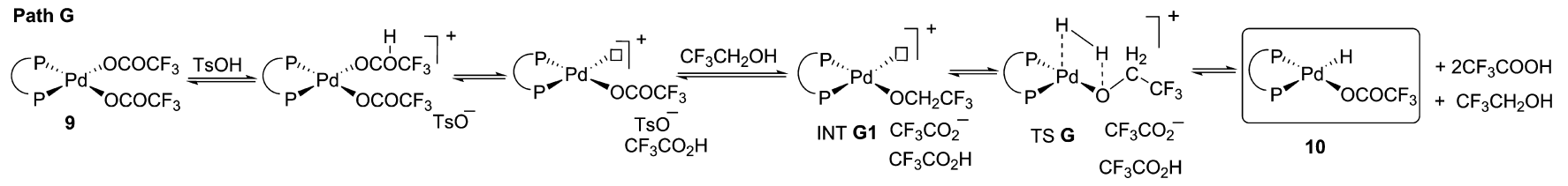

path A because it is much more facile than the other paths. The new path is path $\mathrm{G}$, as shown in Scheme 10. Replacing $\mathrm{CF}_{3} \mathrm{COO}^{-}$with $\mathrm{CF}_{3} \mathrm{CH}_{2} \mathrm{O}^{-}$was found to be endothermic $(\Delta G$ $=7.8 \mathrm{kcal} / \mathrm{mol})$, which is consistent with the fact that $\mathrm{CF}_{3} \mathrm{COOH}$ has not been detected experimentally. The ratedetermining barrier (relative to INT A2, which is the most stable structure prior to the rate-determining step) is calculated to be $29.9 \mathrm{kcal} / \mathrm{mol}$, higher than that of the corresponding nonTFE-participating path by more than $10 \mathrm{kcal} / \mathrm{mol}$. Therefore, the theoretical results do not support that TFE participates in the $\mathrm{Pd}-\mathrm{H}$ formation reaction directly.

Since we ruled out the TFE-participating paths, we began to accept the hypothesis that TFE stabilizes some key intermediates or transition states. This could be true since TFE is a highly polar solvent $(\varepsilon=26.5)$ which is able to stabilize the ions in ionic paths such as path $\mathrm{A}$, and it is inevitable that the barrier of path $\mathrm{A}$ is higher in a less polar solvent. To test this hypothesis, we got the reaction profiles for path $\mathrm{A}$ in $\mathrm{CH}_{2} \mathrm{Cl}_{2}(\varepsilon=8.93)$ for comparison (Figure 5). As

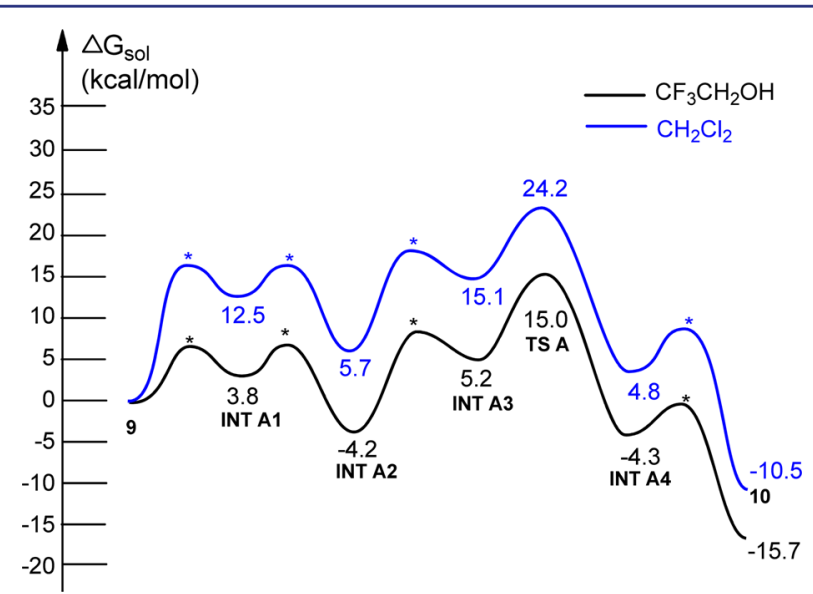

Figure 5. Computed reaction energy profiles for path $\mathrm{A}$ to generate palladium hydride in TFE and $\mathrm{CH}_{2} \mathrm{Cl}_{2}$. Relative free energies in kcal/ mol are given.

expected, we found that in $\mathrm{CH}_{2} \mathrm{Cl}_{2}$ the rate-determining barrier of path A is $24.2 \mathrm{kcal} / \mathrm{mol}$ (relative to Pd catalyst 9), which is $9.2 \mathrm{kcal} / \mathrm{mol}$ higher than in TFE $\left(\Delta G_{\mathrm{CH}_{2} \mathrm{Cl}_{2}}^{\mathrm{TSA}}-\Delta G_{\mathrm{CF}_{3} \mathrm{CH}}^{\mathrm{TSA}}\right)$. The $\Delta G$ of all other ionic intermediates also increases by $8-10$ $\mathrm{kcal} / \mathrm{mol}$. On the basis of these calculations, we proposed that the unique properties of TFE and other fluorinated alcohols stem from their high polarity, which is able to stabilize the ionic intermediates during the catalytic reaction. Generally, the heterolytic splitting of a bond is very difficult and is usually facilitated by the strong solvation effect of the ions. For path $\mathrm{A}$, the barrier is $89.4 \mathrm{kcal} / \mathrm{mol}$ in the gas phase, $24.2 \mathrm{kcal} / \mathrm{mol}$ in $\mathrm{CH}_{2} \mathrm{Cl}_{2}$, and $19.2 \mathrm{kcal} / \mathrm{mol}$ in TFE, which makes it facile under room temperature and high $\mathrm{H}_{2}$ pressure.

As a strong hydrogen bond donor, ${ }^{15 a, 31}$ the hydrogen atom of TFE can interact with the $\mathrm{Pd}-\mathrm{H}$ (Scheme 11). This
Scheme 11. Possible Interaction of the TFE and $\mathrm{Pd}-\mathrm{H}$ Species

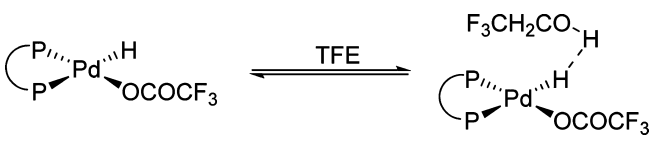

phenomenon was also observed in many other metal hydride species, such as $\mathrm{Ru}-\mathrm{H}$ and $\mathrm{Ni}-\mathrm{H}^{31 \mathrm{a}, \mathrm{c}, 32}$ It is reported that $\mathrm{Ru}-\mathrm{H}$ and $\mathrm{Ni}-\mathrm{H}$ could exchange proton with alcohol solvent (Scheme 12), but this exchange was not observed in the indole hydrogenation because there was no deuteron on the $2-\mathrm{C}$ when $d_{3}$-TFE was subjected to hydrogenation (see eq 2 ).

Scheme 12. Possible Proton Exchange of the TFE and Pd-H Species

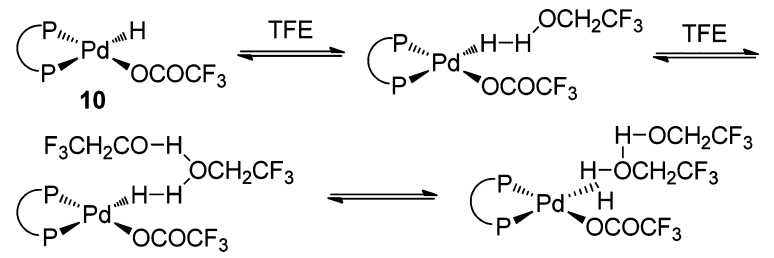

Proposed Catalytic Cycle of Indole Hydrogenation. The catalytic mechanisms for hydrogenation reactions can be classified as (i) inner-sphere or outer-sphere mechanisms on the basis of the interaction between substrate and catalyst, (ii) ionic and non-ionic mechanisms according to the charge separation in the intermediates and transition states, as well as (iii) stepwise and associated mechanisms on the basis of the nature of the reaction pathway. In our search for the most plausible pathway for the indole hydrogenation, we have evaluated four paths including both inner-sphere and outersphere, ionic and non-ionic, stepwise and associated paths. As can be seen from Schemes $13-15$ as well as Figures 6 and 7, path I (Scheme 13, Figure 7), first indole 1a is protonated by $\mathrm{TsOH}$ to give iminium $\boldsymbol{\alpha}$, and then iminium $\boldsymbol{\alpha}$ combines with $\mathrm{Pd}-\mathrm{H}$ to generate INT $\mathbf{1 1} \mathbf{b}$. The next step is the hydride transfer from $\mathrm{Pd}-\mathrm{H}$ to $\boldsymbol{\alpha}$ to generate INT 11c, which subsequently separates into product $\mathbf{2 a}$ and INT A2 and then follows path A to get the active catalyst $\mathrm{Pd}-\mathrm{H}$. This is an outersphere and ionic hydrogenation pathway. Alternatively, 1a can also be protonated by $\mathrm{CF}_{3} \mathrm{COOH}$ (generated in the $\mathrm{Pd}-\mathrm{H}$ formation step) instead of $\mathrm{TsOH}$.

Path II (Scheme 14), protonation of coordinated $\mathrm{CF}_{3} \mathrm{COO}^{-}$ by $\mathrm{TsOH}$ to give INT 12a, followed by associated proton and hydride transfer to give $\mathbf{2 a}$ and INT A2, involves a sixmembered-ring transition state. This is an outer-sphere and non-ionic pathway. Path III is similar to path II except that $\mathrm{CF}_{3} \mathrm{COOH}$ coordinates to $\mathrm{Pd}$ by $\mathrm{C}=\mathrm{O}$ instead of the hydroxyl group. Accordingly, the associated hydrogenation has an eightmembered-ring transition state. 
Scheme 13. Proposed Mechanism for the Asymmetric Hydrogenation of Indoles

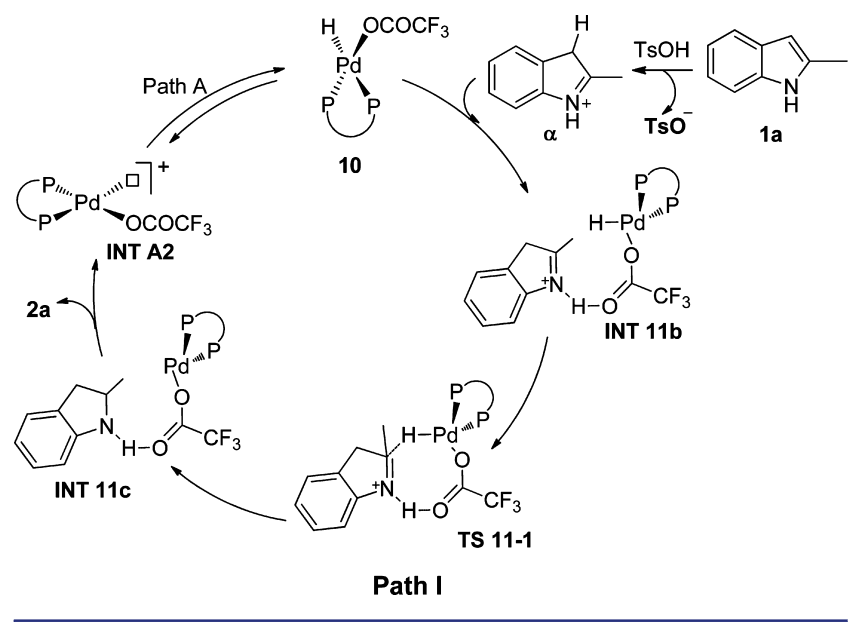

Scheme 14. Associated Pathways II and III for Indole Hydrogenation
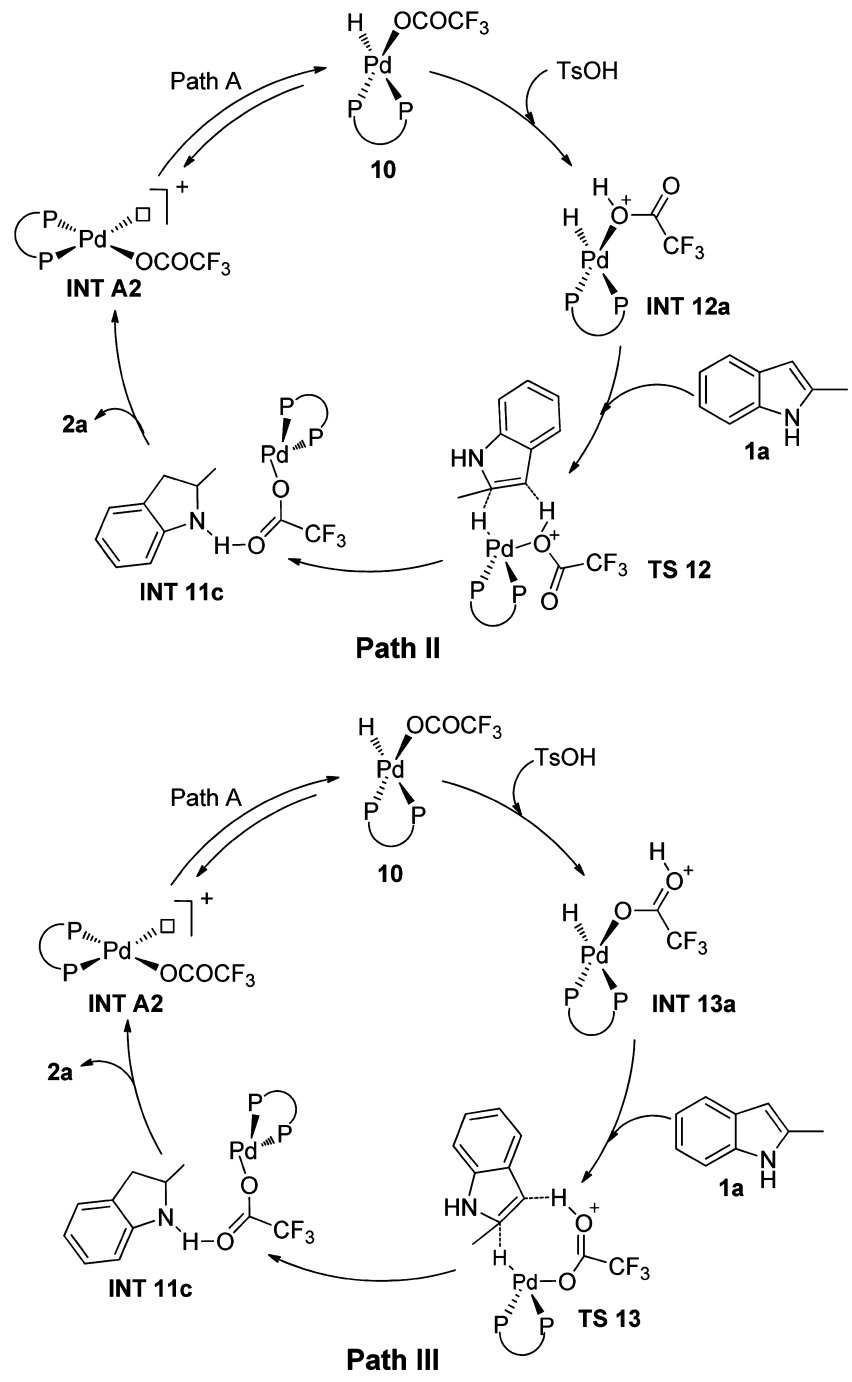

In path IV (Scheme 15), $\mathrm{Pd}-\mathrm{H}$ addition to the $\mathrm{C}=\mathrm{C}$ bond of 1a generates INT 14 first, and then the product $\mathbf{2 a}$ and INT $\mathbf{A 2}$ are generated by proton transfer from $\mathrm{CF}_{3} \mathrm{COOH}$ to
Scheme 15. Inner-Sphere Pathway for Indole Asymmetric Hydrogenation

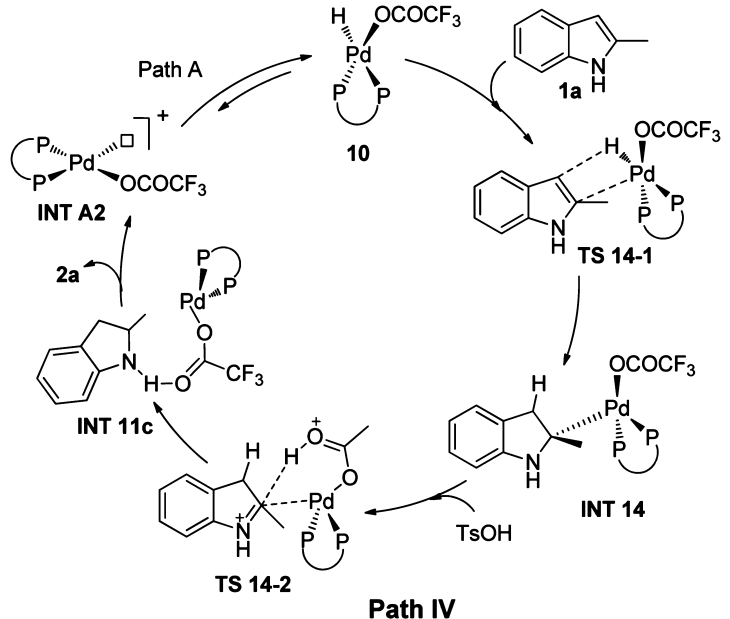

the coordinated iminium. Path IV is an inner-sphere and nonionic pathway.

All four pathways mentioned above have been studied computationally, and the reaction profiles in TFE are shown in Figure 6. Path I was found to be the most plausible one.

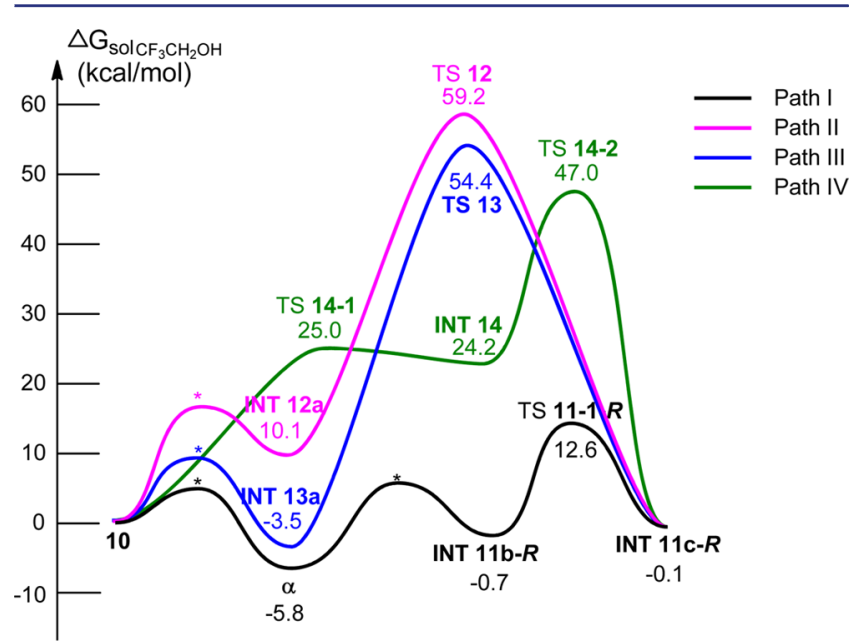

Figure 6. Computed reaction energy profiles for all paths to achieve asymmetric hydrogenation of unprotected indoles in TFE. Relative energies in $\mathrm{kcal} / \mathrm{mol}$ are given.

Protonation of $1 \mathrm{a}$ by $\mathrm{TsOH}$ is thermodynamically favorable $(\Delta G=-5.8 \mathrm{kcal} / \mathrm{mol})$, and the rate-determining step is the hydride transfer. As discussed above, all rate-determining barriers were relative to the most stable structure prior to the rate-determining step, which means $\boldsymbol{\alpha}$ for path I, INT 13a for path III, and $\mathbf{1 0}$ for the other paths. The barriers for formation of $(R)-\mathbf{2 a}$ and $(S)-\mathbf{2 a}$ are 18.4 and $22.7 \mathrm{kcal} / \mathrm{mol}$, respectively (Figure 7). The lower barrier for formation of $(R)-\mathbf{2 a}$ is in good agreement with the high enantioselectivity observed experimentally. In $\mathrm{CH}_{2} \mathrm{Cl}_{2}$, both barriers are slightly lower (17.3 $\mathrm{kcal} / \mathrm{mol}$ for $(R)-2 \mathrm{a}$ and $21.6 \mathrm{kcal} / \mathrm{mol}$ for $(S)-2 \mathrm{a})$ than in TFE. This is because the protonation of $\mathbf{1 a}$ by $\mathrm{TsOH}$ is already quite facile in $\mathrm{CH}_{2} \mathrm{Cl}_{2}$, while TFE overstabilizes the protonated intermediates and lowers its activity.

To confirm that the observed enantioselectivity is not method-dependent, the two key transition states leading to $R$ 


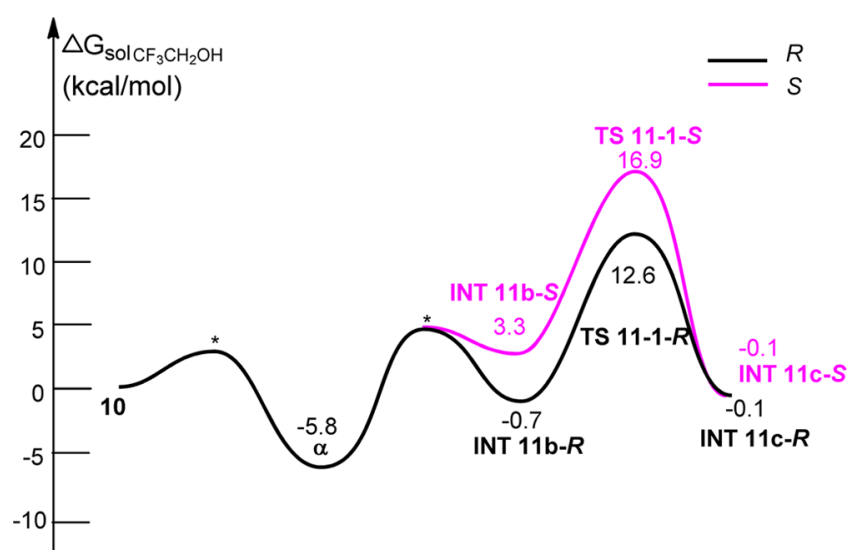

Figure 7. Computed reaction energy profiles for path I to achieve asymmetric hydrogenation of unprotected indoles in TFE. Relative free energies in $\mathrm{kcal} / \mathrm{mol}$ are given.

and $S$ isomers were reoptimized using the M06-2X functional. We found that TS- $R$ is lower in energy $\left(\Delta G\right.$ in $\left.\mathrm{CF}_{3} \mathrm{CH}_{2} \mathrm{OH}\right)$ than TS-S by $3.5 \mathrm{kcal} / \mathrm{mol}$, which is close to the $4.3 \mathrm{kcal} / \mathrm{mol}$ found by the B3LYP functional.

The indole hydrogenation described by this work does not occur without the presence of the strong acids such as L-CSA, $\mathrm{TsOH}$, and $\mathrm{MeSO}_{3} \mathrm{H}$, etc., in contrast to the asymmetric hydrogenation of activated imines catalyzed by Pd complexes. ${ }^{15 e}$ Using $\mathrm{TsOH}$ as the example, we have shown that the strong acid is involved in both the $\mathrm{Pd}-\mathrm{H}$ generation and the hydrogenation. Without strong acid, indole can be protonated by the trifluoroacetic acid generated in the $\mathrm{Pd}-\mathrm{H}$ formation step $(\Delta G=8.0 \mathrm{kcal} / \mathrm{mol})$. The barriers for formation of $(R)-2 \mathrm{a}$ and $(S)-2 \mathrm{a}$ are 26.4 and $30.7 \mathrm{kcal} / \mathrm{mol}$, respectively, both are much higher than those in path $\mathrm{I}$.

Theoretically, a "three-point interaction model" 33 was usually used to explain the high enantioselectivity. According to this model, in order to have enantioselectivity, there must be at least three interactions between the catalyst and the substrate in the transition state, and at least one of those interactions must be stabilizing. Based on this model, in general one would expect that an associate pathway is a better mechanism for the enantioselectivity, and the three points are one steric interaction and two bonding interactions. To understand why path I, a stepwise path, has very good enantioselectivity, we show the transition-states structures (TS 11-1-R and TS 11-1$S$ ) for hydride transfer in Figure 8. Interestingly, we found that both transition states have a strong hydrogen bond between $\mathrm{N}-\mathrm{H}$ of iminium and oxygen of the coordinated $\mathrm{CF}_{3} \mathrm{COO}^{-}$,

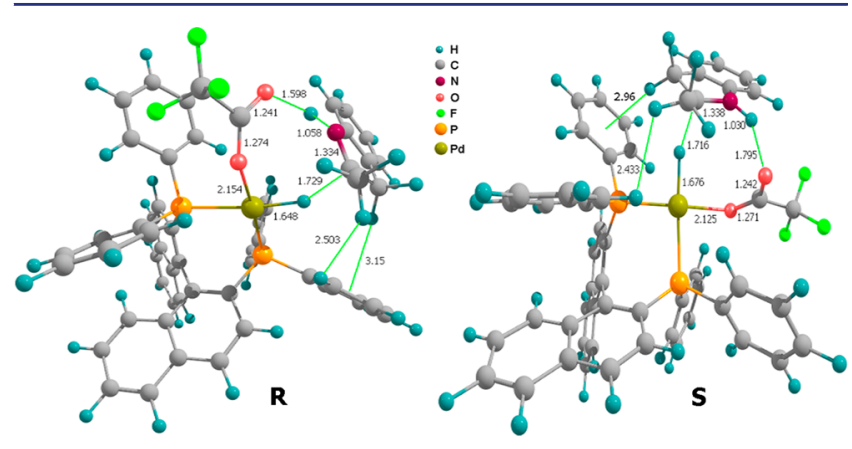

Figure 8. Computed structures of TS 11-1 ( $R$ and $S)$. Bond lengths are given in $\AA$. and there is actually an eight-membered-ring transition state. Therefore, these transition states obey the "three-point interaction model": the $\mathrm{N}-\mathrm{H} \cdots \mathrm{O}$ hydrogen bond, the Pd... $\mathrm{H} \cdots \mathrm{C}$ bond, and the steric interaction between the ligand and the substrate. As shown in Figure 8, the steric interactions come mainly from $\mathrm{CH}_{3}$ of the substrate and $\mathrm{H}(\mathrm{Ph})$ of the chiral ligand $\left(r_{\mathrm{H} \cdots \mathrm{H}}=2.50 \AA \AA\right.$ in TS 11-1-R and 2.43 $\AA$ in TS 11-1-S), as well as $\mathrm{CH}_{2}$ of the substrate and $\mathrm{Ph}$ of the chiral ligand (the distance between $\mathrm{H}\left(\mathrm{CH}_{2}\right)$ and center of $\mathrm{Ph}$ is $3.15 \AA$ for TS 11-1-R and 2.96 Å for TS 11-1-S). We do see a larger steric interaction for TS 11-1-S. In summary, despite the bond interaction and the steric interaction that exist for common stepwise mechanisms, here the hydrogen bond acts as the third point, and is expected to be crucial for the high enantioselectivity. This deduction is also demonstrated by the results of hydrogenation of $\mathrm{N}$-protected indoles, in which either low activity or poor enantioselectivity was obtained due to the absence of the hydrogen bond between $\mathrm{N}-\mathrm{H}$ of iminium and oxygen of coordinated trifluoroacetate (Scheme 3 ).

Paths II and III feature associated hydrogenation, which is usually thought to be found only for asymmetric reactions. The protonation costs $10.1 \mathrm{kcal} / \mathrm{mol}$ for path II and $-3.5 \mathrm{kcal} / \mathrm{mol}$ for path III. The rate-determining steps for paths II and III are the associated hydrogenation steps, with the barrier of 59.2 $\mathrm{kcal} / \mathrm{mol}$ (relative to 10) for path II and $57.9 \mathrm{kcal} / \mathrm{mol}$ (relative to INT 13a) for path III (transition-state structures are shown in Figures 9 and 10). Our calculations suggest that both

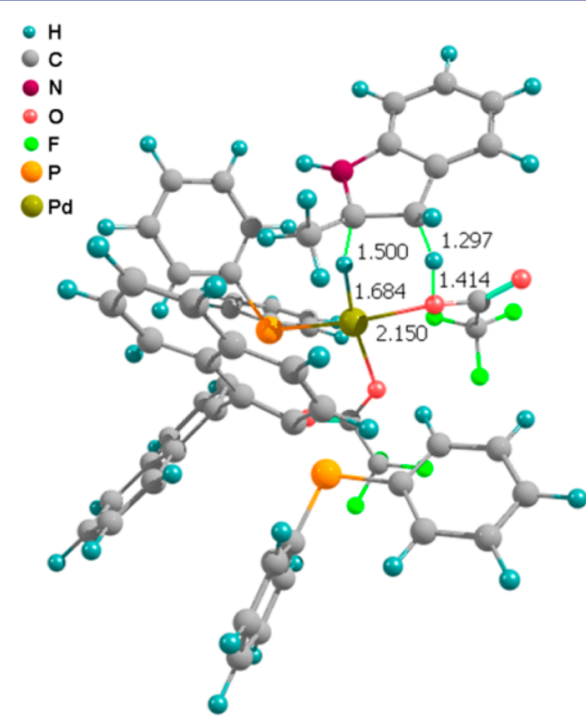

Figure 9. Computed structure of TS 12. Bond lengths are given in $\AA$.

associated pathways degraded to stepwise pathways, where proton transfer to indole is followed by hydride transfer to iminium. Compared with path $\mathrm{I}$, the hydride transfer is the same, while the proton transfer is not competitive because indole is more easily protonated (costs $-5.8 \mathrm{kcal} / \mathrm{mol}$ ) than the coordinated $\mathrm{CF}_{3} \mathrm{COO}^{-}$. For path IV, the barrier for $\mathrm{Pd}-\mathrm{H}$ addition is $25.0 \mathrm{kcal} / \mathrm{mol}$. However, the following proton transfer is much more difficult (energy barrier is $47.0 \mathrm{kcal} / \mathrm{mol}$ relative to 10); therefore, this pathway is not preferred.

Generally, Pd-catalyzed asymmetric hydrogenation includes some important features: (1) Activation of hydrogen gas is a heterolytic process assisted by coordinated trifluoroacetate. (2) This is an ionic hydrogenation process. The hydride is from the hydrogen gas, while the proton is from a Brønsted acid. (3) 


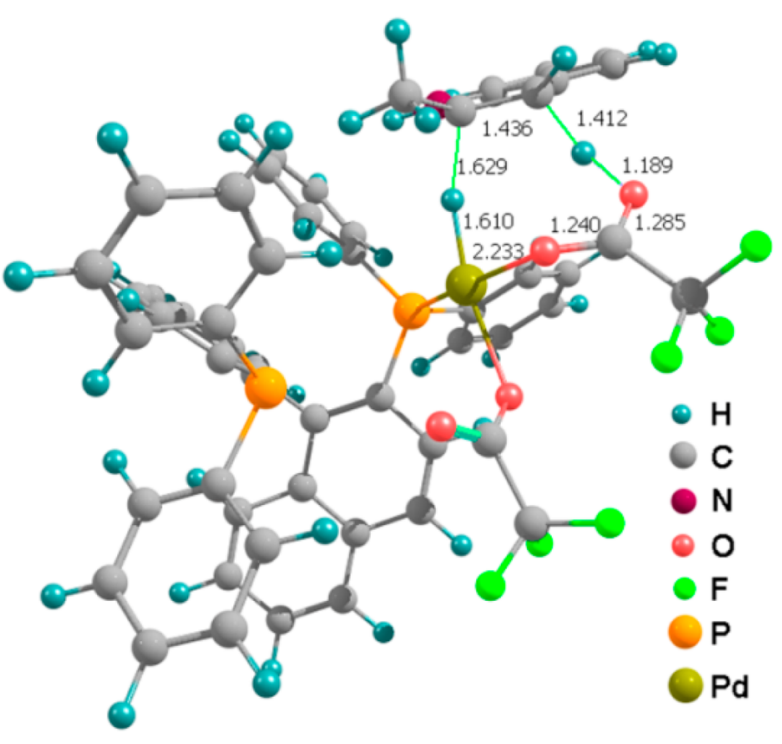

Figure 10. Computed structure of TS 13. Bond lengths are given in $\AA$.

The mechanism is an outer-sphere hydrogenation mechanism. (4) The catalyst is bifunctional, leading to asymmetric hydrogenation and hydrogen-bonding interaction between trifluoroacetate of the $\mathrm{Pd}$ catalyst and iminium salt in the eight-membered-ring transition state for hydride transfer. (5) The highly polar solvent TFE stabilizes the ionic intermediates in active $\mathrm{Pd}-\mathrm{H}$ species generation.

\section{CONCLUSION}

In conclusion, we report an extensive substrate scope for asymmetric hydrogenation of indoles, including 2 -substituted and 2,3-disubstituted indoles. In this process, an equivalent of strong Brønsted acid was necessary to complete the reaction, giving up to $98 \%$ ee. This methodology was also applied in product elaboration for the synthesis of the biologically active indoline skeleton. Notably, a drawback is the low activity and/ or enantioselectivity obtained for the 2-aryl-substituted and electron-withdrawing group located at the 2-position of the indoles. Given the compatibility of a Pd catalyst in this reaction, we also probed the properties of the Pd catalyst and the mechanism of indole hydrogenation by combining experimental studies and DFT calculations. Iminium salt was demonstrated to be the significant active intermediate in this reaction through the isotope-labeled reactions and ESI-HRMS. The strong acid protonates the $\mathrm{C}=\mathrm{C}$ double bond of indole much easier, and therefore can remarkably decrease the energy barrier. According to the ${ }^{1} \mathrm{H}$ NMR spectrum of the $\mathrm{Pd}-\mathrm{H}$ species, which was considered to be the active species, proton exchange between the $\mathrm{Pd}-\mathrm{H}$ active species and solvent TFE could not occur. We have shown that in TFE the $\mathrm{Pd}-\mathrm{H}$ active catalyst is generated by an ionic mechanism in which $\mathrm{H}_{2}$ was split by $\mathrm{Pd}$ and trifluoroacetate via a six-membered-ring transition state. The reaction is only facile at room temperature with the help of the strong Brønsted acid. Highly polar solvent such as TFE is able to stabilize the ionic intermediates, making it better than the other solvents. We also propose that the Pdcatalyzed indole hydrogenation of unprotected indoles undergoes a stepwise, ionic, and outer-sphere hydrogenation mechanism, ${ }^{20,21}$ which features protonation of indole by a strong Brønsted acid and hydride transfer from active $\mathrm{Pd}-\mathrm{H}$ to a protonated indole intermediate. The high enantioselectivity observed experimentally was reproduced by the calculation, and is proposed to arise from the hydrogen-bonding interaction between $\mathrm{N}-\mathrm{H}$ of iminium salt and oxygen of the coordinated trifluoroacetate ligand in the eight-membered-ring transition state for hydride transfer. So, active chiral Pd complex is a typical bifunctional catalyst, leading to asymmetric hydrogenation and hydrogen-bonding interaction between coordinated trifluoroacetate ligand of $\mathrm{Pd}$ catalyst and $\mathrm{N}-\mathrm{H}$ of iminium salt. The above mechanistic study may provide some useful hints for chiral catalysis design and extend the scope of Pd-catalyzed asymmetric hydrogenation.

\section{ASSOCIATED CONTENT}

\section{Supporting Information}

Complete experimental procedures and characterization data for the prepared compounds. This material is available free of charge via the Internet at http://pubs.acs.org.

\section{AUTHOR INFORMATION}

\section{Corresponding Authors}

fanhj@dicp.ac.cn

ygzhou@dicp.ac.cn

\section{Author Contributions}

${ }^{\dagger}$ Y.D. and L.L. contributed equally.

\section{Notes}

The authors declare no competing financial interest.

\section{ACKNOWLEDGMENTS}

This work was supported by by National Natural Science Foundation of China $(21125208,21032003)$ and National Basic Research Program of China (2010CB833300). This paper is dedicated to Prof. Li-Xin Dai on the occasion of his 90th birthday.

\section{REFERENCES}

(1) (a) Southon, I. W.; Buckingham, J. Dictionary of Alkaloids; Chapman and Hall: New York, 1989. (b) Neuss, N.; Neuss, M. N. In The Alkaloids; Brossi, A., Suffness, M., Eds.; Academic Press: San Diego, 1990; p 229. (c) Gueritte, F.; Fahy, J. In Anticancer Agents from Natural Products; Cragg, G. M., Kingstom, D. G. I., Newman, D. J., Eds.; CRC Press: Boca Raton, FL, 2005; p 123. (d) Modern Alkaloids; Fattorusso, E., Taglialatela-Scafati, O., Eds.; Wiley-VCH: Weinheim, 2008, and references therein.

(2) For recent reviews on asymmetric hydrogenation of aromatic compounds, see: (a) Zhao, D.; Glorius, F. Angew. Chem., Int. Ed. 2013, 52, 9616. (b) Wang, D.-S.; Chen, Q.-A.; Lu, S.-M.; Zhou, Y.-G. Chem. Rev. 2012, 112, 2557. (c) Tang, W.; Zhang, X. Chem. Rev. 2003, 103, 3029. (d) Kuwano, R. Heterocycles 2008, 76, 909. (e) Zhou, Y.-G. Acc. Chem. Res. 2007, 40, 1357. (f) Lu, S.-M.; Han, X.-W.; Zhou, Y.-G. Chin. J. Org. Chem. 2005, 25, 634. (g) Glorius, F. Org. Biomol. Chem. 2005, 3, 4171. For recent examples, see: (h) Ye, Z.-S.; Guo, R.-N.; Cai, X.-F.; Chen, M.-W.; Shi, L.; Zhou, Y.-G. Angew. Chem., Int. Ed. 2013, 52, 3685. (i) Iimuro, A.; Yamaji, K.; Kandula, S.; Nagano, T.; Kita, Y.; Mashima, K. Angew. Chem., Int. Ed. 2013, 52, 2046. (j) Ye, Z.S.; Chen, M.-W.; Chen, Q.-A.; Shi, L.; Duan, Y.; Zhou, Y.-G. Angew. Chem., Int. Ed. 2012, 51, 10181. (k) Urban, S.; Beiring, B.; Ortega, N.; Paul, D.; Glorius, F. J. Am. Chem. Soc. 2012, 134, 15241. (1) Kuwano, R.; Morioka, R.; Kashiwabara, M.; Kameyama, N. Angew. Chem., Int. Ed. 2012, 51, 4136. (m) Shi, L.; Ye, Z.-S.; Cao, L.-L.; Guo, R.-N.; Hu, Y.; Zhou, Y.-G. Angew. Chem., Int. Ed. 2012, 51, 8286. (n) Wang, T.; Zhuo, L.-G.; Li, Z. W.; Chen, F.; Ding, Z.; He, Y.; Fan, Q.-H.; Xiang, J.; Yu, Z.-X.; Chan, A. S. C. J. Am. Chem. Soc. 2011, 133, 9878. (o) Urban, S.; Ortega, N.; Glorius, F. Angew. Chem., Int. Ed. 2011, 50, 3803. (p) Ortega, N.; Urban, S.; Beiring, B.; Glorius, F. Angew. Chem., 
Int. Ed. 2012, 51, 1710. (q) Ortega, N.; Tang, D.-T. D.; Urban, S.; Zhao, D.; Glorius, F. Angew. Chem., Int. Ed. 2013, 52, 9500.

(3) (a) Kuwano, R.; Sato, K.; Kurokawa, T.; Karube, D.; Ito, Y. J. Am. Chem. Soc. 2000, 122, 7614. (b) Kuwano, R; Kashiwabara, M.; Sato, K.; Ito, T.; Kaneda, K.; Ito, Y. Tetrahedron: Asymmetry 2006, 17, 521.

(4) Kuwano, R.; Kaneda, K.; Ito, T.; Sato, K.; Kurokawa, T.; Ito, Y. Org. Lett. 2004, 6, 2213.

(5) Kuwano, R.; Kashiwabara, M. Org. Lett. 2006, 8, 2653.

(6) Mrsic, N.; Jerphagnon, T.; Minnaard, A. J.; Feringa, B. L.; de Vries, J. G. Tetrahedron: Asymmetry 2010, 21, 7.

(7) Maj, A. M.; Suisse, I.; Meliet, C.; Agbossou-Niedercorn, F. Tetrahedron: Asymmetry 2010, 21, 2010.

(8) Baeza, A.; Pfaltz, A. Chem.-Eur. J. 2010, 16, 2036.

(9) Wang, D.-S.; Chen, Q.-A.; Li, W.; Yu, C.-B.; Zhou, Y.-G.; Zhang, X. J. Am. Chem. Soc. 2010, 132, 8909.

(10) Wang, D.-S.; Tang, J.; Zhou, Y.-G.; Chen, M.-W.; Yu, C.-B.; Duan, Y.; Jiang, G.-F. Chem. Sci. 2011, 2, 803.

(11) Duan, Y.; Chen, M.-W.; Ye, Z.-S.; Wang, D.-S.; Chen, Q.-A.; Zhou, Y.-G. Chem.-Eur. J. 2011, 17, 7193.

(12) Duan, Y.; Chen, M.-W.; Chen, Q.-A.; Yu, C.-B.; Zhou, Y.-G. Org. Biomol. Chem. 2012, 10, 1235.

(13) Recently, Chen and co-workers developed an asymmetric hydrosilylation of indoles, using combined Lewis base along with Brønsted acid activation to ensure full conversion and high enantioselectivity: Xiao, Y.-C.; Wang, C.; Yao, Y.; Sun, J.; Chen, Y.C. Angew. Chem., Int. Ed. 2011, 50, 10661.

(14) Chen, Q.-A.; Ye, Z.-S.; Duan, Y.; Zhou, Y.-G. Chem. Soc. Rev. 2013, 42, 497.

(15) (a) Abe, H.; Amii, H.; Uneyama, K. Org. Lett. 2001, 3, 313. (b) Suzuki, A.; Mae, M.; Amii, H.; Uneyama, K. J. Org. Chem. 2004, 69, 5132. (c) Wang, Y.-Q.; Zhou, Y.-G. Synlett 2006, 1189. (d) Yang, Q.; Shang, G.; Gao, W.; Deng, J.; Zhang, X. Angew. Chem., Int. Ed. 2006, 45, 3832. (e) Wang, Y.-Q.; Lu, S.-M.; Zhou, Y.-G. J. Org. Chem. 2007, 72, 3729. (f) Wang, Y.-Q.; Yu, C.-B.; Wang, D.-W.; Wang, X.-B.; Zhou, Y.-G. Org. Lett. 2008, 10, 2071. (g) Yu, C.-B.; Wang, D.-W.; Zhou, Y.-G. J. Org. Chem. 2009, 74, 5633. (h) Chen, M.-W.; Duan, Y.; Chen, Q.-A.; Wang, D.-S.; Yu, C.-B.; Zhou, Y.-G. Org. Lett. 2010, 12, 5075. (i) Zhou, X.-Y.; Bao, M.; Zhou, Y.-G. Adv. Synth. Catal. 2011, 353, 84. (j) McLaughlin, M.; Belyk, K.; Chen, C.-Y.; Linghu, X.; Pan, J.; Qian, G.; Reamer, R. A.; Xu, Y. Org. Process Res. Dev. 2013, 17, 1052 .

(16) (a) Yu, C.-B.; Gao, K.; Wang, D.-S.; Shi, L.; Zhou, Y.-G. Chem. Commun. 2011, 47, 5052. (b) Yu, C.-B.; Gao, K.; Chen, Q.-A.; Chen, M.-W.; Zhou, Y.-G. Tetrahedron Lett. 2012, 53, 2560.

(17) (a) Raja, R.; Thomas, J. M.; Jones, M. D.; Johnson, B. F. G.; Vaughan, D. E. W. J. Am. Chem. Soc. 2003, 125, 14982. (b) Wang, Y.Q.; Lu, S.-M.; Zhou, Y.-G. Org. Lett. 2005, 7, 3235. (c) Goulioukina, N. S.; Bondarenko, G. N.; Bogdanov, A. V.; Gavrilov, K. N.; Beletskaya, I. P. Eur. J. Org. Chem. 2009, 510. (d) Wang, C.; Yang, G.; Zhuang, J.; Zhang, W. Tetrahedron Lett. 2010, 51, 2044. (e) Teng, B.; Zheng, J.; Huang, H.; Huang, P. Chin. J. Chem. 2011, 29, 1312. (f) Zhou, X.-Y.; Wang, D.-S.; Bao, M.; Zhou, Y.-G. Tetrahedron Lett. 2011, 52, 2826.

(18) (a) Drago, D.; Pregosin, P. S. Organometallics 2002, 21, 1208. (b) Jones, M. D.; Raja, R.; Thomas, J. M.; Johnson, B. F. G.; Lewis, D. W.; Rouzaud, J.; Harris, K. D. M. Angew. Chem., Int. Ed. 2003, 42, 4326. (c) Tsuchiya, Y.; Hamashima, Y.; Sodeoka, M. Org. Lett. 2006, 8, 4851. (d) Monguchi, D.; Beemelmanns, C.; Hashizume, D.; Hamashima, Y.; Sodeoka, M. J. Organomet. Chem. 2008, 693, 867. (e) Arnanz, A.; González-Arellano, C.; Juan, A.; Villaverde, G.; Corma, A.; Iglesias, M.; Sánchez, F. Chem. Commun. 2010, 46, 3001. (f) Boronat, M.; Corma, A.; González-Arellano, C.; Iglesias, M.; Sánchez, F. Organometallics 2010, 29, 134. (g) Wang, D.-S.; Wang, D.W.; Zhou, Y.-G. Synlett 2011, 947.

(19) (a) Wang, D.-S.; Ye, Z.-S.; Chen, Q.-A.; Zhou, Y.-G.; Yu, C.-B.; Fan, H.-J.; Duan, Y. J. Am. Chem. Soc. 2011, 133, 8866. (b) Li, C.; Chen, J.; Fu, G.; Liu, D.; Liu, Y.; Zhang, W. Tetrahedron 2013, 69, 6839.
(20) (a) Zhu, Y.; Burgess, K. Acc. Chem. Res. 2012, 45, 1623. (b) Zhou, J.; Ogle, J. W.; Fan, Y.; Banphavichit, V.; Zhu, Y.; Burgess, K. Chem.-Eur. J. 2007, 13, 7162. (c) Perry, M. C.; Cui, X. H.; Powell, M. T.; Hou, D. R.; Reibenspies, J. H.; Burgess, K. J. Am. Chem. Soc. 2003, 125, 113. (d) O, W. W. N.; Lough, A. J.; Morris, R. H. Organometallics 2012, 31, 2152. (e) Maeda, T.; Makino, K.; Iwasaki, M.; Hamada, Y. Chem.-Eur. J. 2010, 16, 11954. (f) Hopmann, K. H.; Bayer, A. Organometallics 2011, 30, 2483. (g) Fan, Y. B.; Cui, X. H.; Burgess, K.; Hall, M. B. J. Am. Chem. Soc. 2004, 126, 16688. (h) Dobereiner, G. E.; Nova, A.; Schley, N. D.; Hazari, N.; Miller, S. J.; Eisenstein, O.; Crabtree, R. H. J. Am. Chem. Soc. 2011, 133, 7547.

(21) (a) Sandoval, C. A.; Ohkuma, T.; Utsumi, N.; Tsutsumi, K.; Murata, K.; Noyori, R. Chem.-Asian J. 2006, 1, 102. (b) Sandoval, C. A.; Ohkuma, T.; Muniz, K.; Noyori, R. J. Am. Chem. Soc. 2003, 125, 13490. (c) Phillips, S. D.; Fuentes, J. A.; Clarke, M. L. Chem.-Eur. J. 2010, 16, 8002. (d) Kitamura, M.; Tsukamoto, M.; Bessho, Y.; Yoshimura, M.; Kobs, U.; Widhalm, M.; Noyori, R. J. Am. Chem. Soc. 2002, 124, 6649. (e) Girard, C.; Genet, J. P.; Bulliard, M. Eur. J. Org. Chem. 1999, 2937. (f) Ashby, M. T.; Halpern, J. J. Am. Chem. Soc. $1991,113,589$.

(22) (a) Roucoux, A.; Thieffry, L.; Carpentier, J. F.; Devocelle, M.; Meliet, C.; Agbossou, F.; Mortreux, A. Organometallics 1996, 15, 2440. (b) Kless, A.; Borner, A.; Heller, D.; Selke, R. Organometallics 1997, 16, 2096. (c) Imamoto, T.; Tamura, K.; Zhang, Z.; Horiuchi, Y.; Sugiya, M.; Yoshida, K.; Yanagisawa, A.; Gridnev, I. D. J. Am. Chem. Soc. 2012, 134, 1754. (d) Heller, D.; Kadyrov, R.; Michalik, M.; Freier, T.; Schmidt, U.; Krause, H. W. Tetrahedron: Asymmetry 1996, 7, 3025. (e) Haag, D.; Runsink, J.; Scharf, H. D. Organometallics 1998, 17, 398. (f) Gridnev, I. D.; Imamoto, T.; Hoge, G.; Kouchi, M.; Takahashi, H. J. Am. Chem. Soc. 2008, 130, 2560. (g) Gridnev, I. D.; Higashi, N.; Asakura, K.; Imamoto, T. J. Am. Chem. Soc. 2000, 122, 7183. (h) Fabrello, A.; Bachelier, A.; Urrutigoity, M.; Kalck, P. Coord. Chem. Rev. 2010, 254, 273.

(23) (a) Ettel, V.; Myska, J. Chem. Abstr. 1956, 5619. (b) Ettel, V.; Myska, J. Collect. Czech. Chem. Commun. 1956, 21, 473. (c) Zhao, H.; He, X. S.; Thurkauf, A.; Hoffman, D.; Kieltyka, A.; Brodbeck, R.; Primus, R.; Wasley, J. W. F. Bioorg. Med. Chem. Lett. 2002, 12, 3111. (d) Zhao, H.; Thurkauf, A.; He, X. S.; Hodgetts, K.; Zhang, X. Y.; Rachwal, S.; Kover, R. X.; Hutchison, A.; Peterson, J.; Kieltyka, A.; Brodbeck, R.; Primus, R.; Wasley, J. W. F. Bioorg. Med. Chem. Lett. 2002, 12, 3105.

(24) (a) Chen, C.-B.; Wang, X.-F.; Cao, Y.-J.; Cheng, H.-G.; Xiao, W.-J. J. Org. Chem. 2009, 74, 3532. (b) Hinman, R. L.; Shull, E. R. J. Org. Chem. 1961, 26, 2339. (c) Ballini, R.; Palmieri, A.; Petrini, M.; Shaikha, R. R. Adv. Synth. Catal. 2008, 350, 129. (d) Li, Y.; Shi, F.-Q.; He, Q.-L.; You, S.-L. Org. Lett. 2009, 11, 3182. (e) Zheng, B.-H.; Ding, C.-H.; Hou, X.-L.; Dai, L.-X. Org. Lett. 2010, 12, 1688. (f) Jing, L.; Wei, J.; Zhou, L.; Huang, Z.; Li, Z.; Wu, D.; Xiang, H.; Zhou, X. Chem.-Eur. J. 2010, 16, 10955.

(25) (a) Grushin, V. V. Chem. Rev. 1996, 96, 2011. (b) Hills, I. D.; Fu, G. C. J. Am. Chem. Soc. 2004, 126, 13178. (c) Konnick, M. M.; Gandhi, B. A.; Guzei, I. A.; Stahl, S. S. Angew. Chem., Int. Ed. 2006, 45, 2904. (d) Nielsen, R. J.; Goddard, W. A. J. Am. Chem. Soc. 2006, 128, 9651. (e) Popp, B. V.; Stahl, S. S. J. Am. Chem. Soc. 2007, 129, 4410. (f) Konnick, M. M.; Stahl, S. S. J. Am. Chem. Soc. 2008, 130, 5753. (g) Popp, B. V.; Stahl, S. S. Chem.-Eur. J. 2009, 15, 2915. (h) Decharin, N.; Stahl, S. S. J. Am. Chem. Soc. 2011, 133, 5732. (i) Sigman, M. S.; Jensen, D. R. Acc. Chem. Res. 2006, 39, 221. (j) Gligorich, K. M.; Schultz, M. J.; Sigman, M. S. J. Am. Chem. Soc. 2006, 128, 2794. (k) Schultz, M. J.; Adler, R. S.; Zierkiewicz, W.; Privalov, T.; Sigman, M. S. J. Am. Chem. Soc. 2005, 127, 8499.

(26) (a) Leoni, P.; Sommovigo, M.; Pasquali, M.; Midollini, S.; Braga, D.; Sabatino, P. Organometallics 1991, 10, 1038. (b) Portnoy, M.; Frolow, F.; Milstein, D. Organometallics 1991, 10, 3960. (c) Leoni, P.; Pasquali, M.; Sommovigo, M.; Laschi, F.; Zanello, P.; Albinati, A.; Lianza, F.; Pregosin, P. S.; Rueegger, H. Organometallics 1993, 12, 1702. (d) Portnoy, M.; Milstein, D. Organometallics 1994, 13, 600. (e) Fantasia, S.; Egbert, J. D.; Jurčík, V.; Cazin, C. S. J.; Jacobsen, H.; Cavallo, L.; Heinekey, D. M.; Nolan, S. P. Angew. Chem., Int. Ed. 2009, 
48, 5182. (f) Fulmer, G. R.; Muller, R. P.; Kemp, R. A.; Goldberg, K. I. J. Am. Chem. Soc. 2009, 131, 1346. (g) Fulmer, G. R.; Herndon, A. N.; Kaminsky, W.; Kemp, R. A.; Goldberg, K. I. J. Am. Chem. Soc. 2011, 133, 17713. (h) Vyas, D. J.; Larionov, E.; Besnard, C.; Guénée, L.; Mazet, C. J. Am. Chem. Soc. 2013, 135, 6830.

(27) All calculations were carried out using Density Functional Theory as implemented in the Jaguar 7.5 suite of ab initio quantum chemistry programs. Geometry optimizations were performed with the B3LYP functional and the $6-31 \mathrm{G}^{* *}$ basis set with no symmetry restrictions. Palladium was represented using the Los Alamos LACVP basis. Solvation energies were evaluated by a self-consistent reaction field (SCRF) approach based on accurate numerical solutions of the Poisson-Boltzmann equation. The free energy in solution phase was calculated as $G($ sol $)=E($ SCF $)+\mathrm{ZPE}-T S($ gas $)+G^{\text {solv }}$.

(28) Fey, N.; Ridgway, B. M.; Jover, J.; McMullin, C. L.; Harvey, J. N. Dalton Trans. 2011, 40, 11184.

(29) (a) Bonnet-Delpon, D.; Bégué, J.-P.; Crousse, B. Synlett 2004, 18. (b) Börner, A.; Shuklov, I.; Dubrovina, N. Synthesis 2007, 2007, 2925.

(30) (a) Eberson, L.; Hartshorn, M. P.; Persson, O.; Radner, F. Chem. Commun. 1996, 2105. (b) Munshi, P.; Main, A. D.; Linehan, J. C.; Tai, C.-C.; Jessop, P. G. J. Am. Chem. Soc. 2002, 124, 7963.

(31) (a) Guari, Y.; Ayllon, J. A.; Sabo-Etienne, S.; Chaudret, B.; Hessen, B. Inorg. Chem. 1998, 37, 640. (b) Fache, F.; Piva, O. Synlett 2004, 1294. (c) Ng, S. M.; Yin, C.; Yeung, C. H.; Chan, T. C.; Lau, C. P. Eur. J. Inorg. Chem. 2004, 2004, 1788. (d) Vuluga, D.; Legros, J.; Crousse, B.; Slawin, A. M. Z.; Laurence, C.; Nicolet, P.; BonnetDelpon, D. J. Org. Chem. 2011, 76, 1126.

(32) (a) Teunissen, H. T. Chem. Commun. 1998, 1367. (b) Bakhmutova, E. V.; Bakhmutov, V. I.; Belkova, N. V.; Besora, M.; Epstein, L. M.; Lledos, A.; Nikonov, G. I.; Shubina, E. S.; Tomas, J.; Vorontsov, E. V. Chem.-Eur. J. 2004, 10, 661. (c) Donghi, D.; Beringhelli, T.; D'Alfonso, G.; Mondini, M. Chem.-Eur. J. 2006, 12, 1016. (d) Dub, P. A.; Fillipov, O. A.; Silantyev, G. A.; Belkova, N. V.; Daran, J.-C.; Epstein, L. M.; Poli, R.; Shubina, E. S. Eur. J. Inorg. Chem. 2010, 1489.

(33) (a) Easson, L. H.; Stedman, E. J. Biochem. 1933, 27, 1257. (b) Simón, L.; Goodman, J. M. J. Am. Chem. Soc. 2008, 130, 8741. 